\title{
PERIODICITY AND PROGRESSIVE CHANGE IN CONTINUOUS MENTAL WORK.
}

BY C. E. SEASHORE Pb.D., AND GRALE HELEN KENT, A.M.

This study of the fluctuations in the efficiency of continuous mental work deals with three distinct processes: sensibility, discrimination, and memory. The experiments accordingly fall into three series. The common aim in all the series was to secure records of continuous work in representative processes under satisfactory experimental conditions. The most essential of such conditions were that the processes should be natural, definite, controllable, repeatable, recordable, and relatively free from varying associations, and that the elements of the processes should be as constant as possible, even throughout long-continued repetition. ${ }^{1}$

Fatigue $^{2}$ was the primary object of interest and search, but that illusive yet ever intrusive factor is almost hopelessly lost in the umbrage of related processes. Our leading effort has been to secure reliable and analyzable records of work done, then to discover the actual fluctuations in such work, and eventually to trace in part the rôles played by known factors as causes of these fluctuations. ${ }^{3}$

\section{Series I. Sensibility. \\ Problem, Apparatus, Method, and Observers.}

The experiments in this series deal with the fluctuations in auditory sensibility which result from continuous work in listening to a liminal tone. The act which constituted the work con-

1 The writers of this article are deeply indebted to the work of Dr. Florence Brown Sherbon whose experiments on the same subject, in this laboratory, preceded the present research. Both in the planning of our experiments and in the interpretation of the results, we have used freely the knowledge gained throngh the earlier work.

'My article on 'The Experimental Study of Mental Fatigue,' PSYCH. BCI,., r904, I., 97-Ior, constitutes the logical introduction to this report. C. E. S.

${ }^{3}$ The reader may profitably turn to Part IV. and read the 'General Conclusions ' first; he will theu be able to read the detailed account of the experiments more critically, having the full scope of the work in view. 
sisted in dctermining the moments of appearance and disappcarance of a tone which oscillated 'incessantly' about the threshold. In the following discussion, one such double determination will be spoken of as a single act - the act. The work of the whole period of an experiment consisted in the continuous repetition of this simple act. The serial record of the two thresholds which were thus determined constituted the measurement.

The stimulus was a continuous tone of variable intensity, produced by a roo v.d. electric tuning-fork, through the audiometer.

Since some idea of the construction of the audiometer is necessary for the understanding of this report, we herewith insert, for the convenience of the reader, some extracts from the original description. ${ }^{1}$

\section{THE AUDIOMETER.}

The essential and unique feature of this apparatus consists in the method of varying and measuring the relative intensity of the sound. This is accomplished by applying the principle that, for certain given relations between the

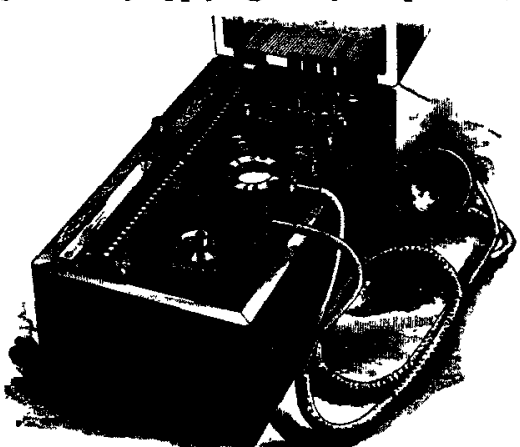
primary and the secondary coils of an induction coil, the induced current varies directly with the number of turns of wire in the secondary coil. The complete apparatus consists of an induction coil, a battery, a galvanometer, a resistance coil, switches and a telephone receiver, all except the receiver being built into one compact and portable piece.

A dry battery is so connected that it may be thrown into the primary circait of the induction coil by turuing the left-hand switch. The galvanometer, seen through the crystal in the center, may be thrown into circuit by turning the right-hand switch. The fall of potential over the primary coil is reduced to the standard e.m.f., by varying the resistance by means of the plugs at the farther end of the chest and gauging it by the galvanometer. The resistance permits of as small variations as can be detected by the galvanometer; and the galvanometer detects smaller variations in the current than can be detected by the ear at the receiver. The lever at the near end of the chest is a key which is used for the rapid closing and opening of the primary circuit in producing the stimulus. No current is drawn except for the moment that the circuit is closed by this key. The primary coil is longer than the secondary. The latter is wound in forty sections, arranged in a series according to the number of

'Seashore, 'An Audiometer,' Univ. of Iowa Stud. in Psych., 1898, II., I58I63. 
turns of wire that each contains, as may be seen in the accompanying table. Each of these sections is so connected with the surface terminals along the scale that the spring contact on the sliding carriage throws into circuit the number of sections indicated by the numbers on the scale. Therefore, to vary the energy communicated to the receiver in this circuit, it is necessary only to move the carriage along the scale to the proper terminal. As it is most conve nient to vary the stimulus in a geometric ratio according to the psycho-physic law, this principle has been taken as a guide in determining the scale of intensities of the sound. The numbers on the audiometer scale are given in the first column in the accompanying table; these indicate the corresponding number of sections involved in the secondary circuit. The second column gives the corresponding number of physical units in terms of the total number of turns of wire in circuit. The ratio of the increments in the sound is such that the forty steps in the series are, as nearly as can be determined, psychologically equal. The serial numbers on the scale are used in all readings. These measurements all refer to the strength of the current which energizes the receiver. The functional relation between the strength of current and the amplitude of vibration in the receiver is somewhat complex, but for the present purpose it may be regarded as fairly uniform.

\section{Table of Values for the Audiometcr Sale.}

\begin{tabular}{rr|rr|rr|r|r|r|r|r}
$I$. & $I I$. & $I$. & $I I$. & $I$. & $I I$. & $I$. & $I I$. & $I$. & $I I$. \\
I & I & 9 & 9 & 17 & 32 & 25 & 107 & 33 & 368 \\
2 & 2 & 10 & 11 & I & 37 & 26 & 125 & 34 & 429 \\
3 & 3 & II & 13 & 19 & 43 & 27 & 146 & 35 & 500 \\
4 & 4 & 12 & 15 & 20 & 50 & 28 & 170 & 36 & 583 \\
5 & 5 & 13 & 17 & 21 & 58 & 29 & 198 & 37 & 680 \\
6 & 6 & 14 & 20 & 22 & 68 & 30 & 231 & 38 & 793 \\
7 & 7 & 15 & 23 & 23 & 79 & 31 & 270 & 39 & 925 \\
8 & 8 & 16 & 27 & 24 & 92 & 32 & 315 & 40 & 1079
\end{tabular}

I., scale on the audiometer.

$I I$., corresponding values, $i . e$, number of coils in the secondary circuit.

The range of the intensity of the sound is such that it is not probable that any person can hear the weakest sound and all who can hear ordinary conversation at all can hear the strongest sound. The average threshold for normal ears lies near the middle of the scale.

For certain tests by aurists and experiments in the psychological laboratory, it is desirable to have a tone instead of a click for stimulus. Provision has been made for the production of tones in the audiometer. The inside connections are so arranged that by attaching a double contact electric tuning. fork to the binding posts seen to the right, the fork may be made to interrupt the primary circuit of the audiometer and thus produce the tone of the fork in the receiver. This tone may be varied and measured in the same way as the regular stimulus.

An electric sounder in the measuring-room was connected with a light strap key held freely in the hand of the observer in the observing-room. The motor process which was necessarily involved in the act as defined above, and constituted the response of the observer, consisted in keeping the key closed when he heard the sound and open when he did not hear it. 
The strength of the sound at the time of closing the key was recorded as the upper limit of the threshold and at the time of opening the key as the lower limit of the threshold. These two limits may be called, respectively, $T_{0}$ and $T_{u}$ (" threshold over and threshold under').

The intensity of the sound was varied by moving the carriage of the audiometer over the scale of psychologically equal units of difference in intensity. The experimenter was guided by a metronome in moving the carriage at the rate of one step per second. Starting at a point below the threshold, the carrier was moved upward at this uniform rate until the $T o$ signal indicated that the sound was heard; the direction of movement was then immediately reversed and continued at the same rate until the $T u$ signal was heard indicating that the sound had become inaudible; the direction of movement was then immediately reversed again and continued as before, thus making a continuous oscillation about the actual threshold throughout the whole experiment. It is evident, therefore, that the quality of the record depended upon the alertness of the observer and that the height, width, and uniformity of the threshold constitute relative measures of the efficiency of the observer at any given time.

Each experiment was continued two hours, which is a long period for continuous and homogeneous work, and probably long enough to bring out the normal fluctuations for any ordinary single period of work. The observer was seated as comfortably as possible in the observing room. ${ }^{1}$ The room was dark and quiet and there was no avenue of communication except the signals described. The observing room is $12^{\prime} 2^{\prime \prime} \times 12^{\prime} 7^{\prime \prime} \times 10^{\prime} 8^{\prime \prime}$. No ventilation was carried on during the experiment period, but the room was thoroughly ventilated with fresh air by an electric fan just before each experiment and the observer was alone in the room.

The experimenter had an assistant to record the readings

${ }^{1}$ This room is described in Univ. of Iowa Stud. in Psych., 1902, III., I40. Ordinarily it is relatively sound-proof, light-proof, and jar-proof, but at the time of these experiments, there was a temporary disarrangement by which this room made contact with the main building. Therefore it was not so quiet as would have been desirable: strong sounds from the outside could penetrate faintly. 
from the audiometer and to divide the record into five-minute periods. In all except experiments III. and X., a telephone receiver with a head clasp was used and tied lightly to the head of the observer with a band in order to secure constant adjustment. Other particular precautions will be discussed later.

The conditions thus briefly described comply fairly with the requirements as laid down at the outset. The act was natural - 'Hold the key down while you hear the sound.' It was definite: the only question which should arise was, "Do I or do I not hear that particular sound' - and that was the question continually in the mind; the audibility of the sound at every moment was the element measured ; the act was simple, familiar, and clear cut. It was controllable; the stimulus was under control, and ordinary disturbances were excluded. It was repeatable; the setting did not change by repetition and the progressive change in the internal nature of the act was open to analysis on the ground of known conditions.

The real work was in the cognitive process. The motor process was practically automatic; it was not wearing but, on the other hand, afforded a sense of relief from the otherwise restricted attitude.

While this positive statement of successful attainments is true in the relative sense in which we describe and control psychological conditions, the very rigidity of the conditions revealed shortcomings not otherwise noticeable, and no one can be more cognizant of these than the experimenters. Even if not expressly eliminated, such factors will be duly weighed before reaching our final conclusion.

There are two fundamental factors in a continued threshold test of this kind. One is the change in the physiological irritability of the peripheral organ and the other is change in the central power of concentration of attention. The latter would be the same for the two ears; therefore any change in the sensibility of the unused ear that may take place during the experiment is probably central. This fact suggests a simple test which would seem to be concise and crucial, but we encountered very serious obstacles in the way of controlling the conditions. Immediately before and immediately after the two-hour period, 
a test of twenty trials was made upon each ear, in the double fatigue order, by the same method that was followed in the main experiment. The object was to determine the threshold of each ear, under similar conditions, when rested and when fatigued.

There are ten experiments in this series taken on as many observers, but all under similar conditions. The observers in experiments I., III., IV., VI., VII., VIII., and IX. are men and in experiments II., V., and X. women. These ten persons represent widely different degrees of practice, general efficiency in observing, and endurance. I. (D. S.), scholar in psychology, was thoroughly familiar with the situation and the conditions of the experiment. II. (G. H. K.), also scholar in psychology, and III. (C. E. S.) were the writers. X. (A. W.) was a first-year student in psychology, somewhat familiar with laboratory methods, but was not trained as an observer. The other observers were all students in the technical laboratory course and, with the exception of VIII. (O. H.), had had more than half a year of training as observers in the course. All knew the purpose and conditions of the experiment and took an active interest in it; but none of the observers, except the experimenters, had seen any other record of the kind.

Each observer was allowed a preliminary practice of from two to five minutes, according to need, - enough to make the requirements and the nature of the experiment clear. This small amount of practice was quite sufficient because the act was extremely simple and all, except obșerver X., had previously served both as observers and experimenters in the measurin , of hearing ability by this very method and apparatus.

\section{Explanation of the Records.}

The records consist of two series of numbers representing, respectively, the successive readings for the just perceptible sound, $T o$, and the just non-perceptible sound, $T u$. The num. bers of each series were averaged by tens and by hundreds, and the mean variation found for each group of ten. Instead of printing tables, we present the results in the form of curves. This method is economical and throws the results into a better single perspective than could be obtained from the tables alone. 


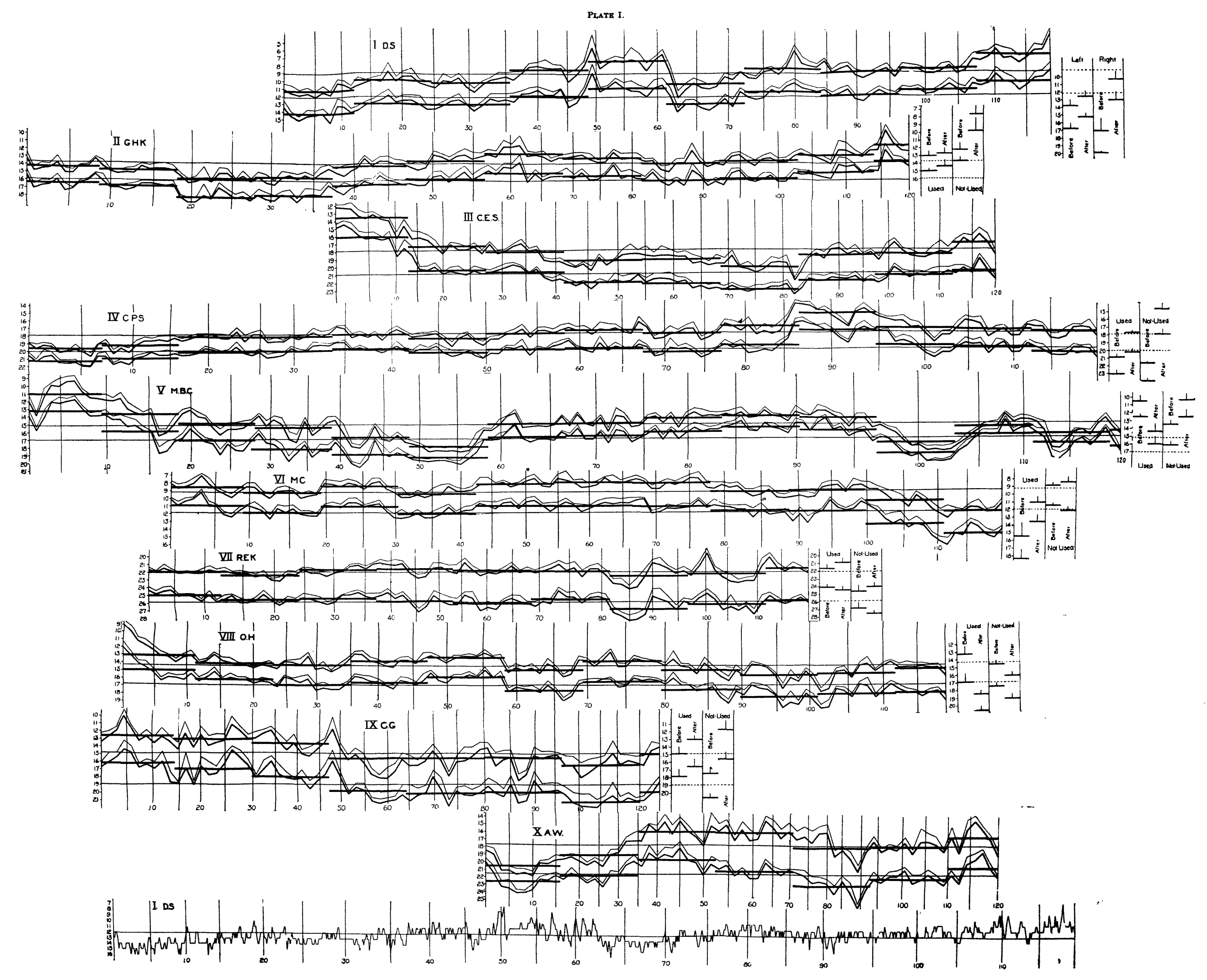


These curves constitute Fig's I. to X. in Plates I., II., and III. Fig. I. $a$, in Pl. I. is a representation in detail of the To-measurements of experiment I., Fig. I., which will be explained later.

Each of the curves represents a two-hour record of one observer. The vertical lines divide the records into five-minute sections. The light horizontal lines which extend the full length of the record show the average for the entire period, the lower being $T o$ and the upper $T u$. The heavy horizontal bars mark the averages by hundreds. The heavy zigzags show the averages by tens, and the light zigzags, which are drawn on the heavy zigzags as base, show the mean variation for each of these tens. The figures at the left end give the scale of intensities in terms of the readings of the audiometer. For the purpose in hand, it is sufficient to remember that the smaller the number, the better the sensibility; so that the higher a point in the curve is, the keener sensibility it represents.

The audiometer was adjusted to different standards for different observers, in order to bring the threshold within the most convenient range of the scale; hence the absolute heights of the thresholds for different observers are not to be compared.

The observers indicated, by signals, the time of all special disturbance and had separate signals for subjective and objective disturbances. In the tabulation of the results the record of the act at such a signal was recognized only for its time-value.

The results of the before- and after-tests are represented graphically at the right end of each curve. The long averagelines of the main record are represented by dotted lines for the purpose of facilitating comparison. The horizontal lines show the average $T_{0}$ and $T u$ before and after. Each is the average of twenty trials, the mean variation of which is represented by a vertical line upon the horizontal. The units in the scale of intensities are on the same scale as in the main curves.

\section{Criteria of Change.}

At least three criteria may be taken into consideration in an attempt to evaluate the efficiency of the work represented in these records. They are: (I) The height of the threshold; (2) the mean variation; and (3) the width of the threshold. 
The first is self-evident: the higher the curve, the keener the sensibility. It is a quantitative measurement.

The mean variation may be large or small regardless of whether the sensibility is keen or dull. In this experiment it is probably not a measure of the sensibility of the sense organ, but of the power of concentration of attention. It is, however, a measure only so long as there is a continuous, maximum effort of concentration, which is the condition sought in these experiments. Even then it must be interpreted with great precaution and only in the light of introspective accounts.

The width of the threshold, which is the difference between $T o$ and $T u$, depends upon the alertness of the observer. Slow reaction tends to give a low $T o$ and a high $T u$, thus increasing the difference in both directions. A wide threshold means a long act; hence the number of acts in a given period varies inversely with the width of the threshold. The width of the threshold in records III. and X. is due in part to the method of reaction employed by the experimenter in these which were the first two experiments, but the method was uniform throughout the records. With this limitation, the characteristic width of each record is probably an expression of the personal equation of the observer. It may be assumed, other things being equal, that a narrow threshold indicates alertness, $i$. e., steady keenness in discriminative attention. The principal counter-factor is the tendency to automatism. The automatism is at least favored by the approximate coincidence of the time of hearing with the high crest of the normal attention-wave. The feeling of 'let it go' came not only from the physical change in the stimulus but also from the termination of the subjective attentionwave. One of the writers experienced that very distinctly in the special experiment on that point (see p. 60, following).

Before we make any physiological or psychological interpretation of the records, we must inquire whether the flucluations may not be due to changes in the stimulus. We have taken every precaution to keep it constant. The receiver on the audiometer is of good quality and well seasoned; we used the Edison-Lelande cells; the temperature was practically constant; as the interruption by the fork took place in a shunt cir- 
cuit, the main circuit remained permanently closed; and the current was minimal so that there could not be serious danger from permanent self-induction. Therefore, although we have no absolute proof of the constancy of the stimulus, we must proceed on the assumption that it remained at the same standard. We may also invoke the evidences obtained in other series of experiments and especially those on sight. As will be seen, the conclusions drawn from this series on sensibility are all corroborated by the experiments in the two following series. They were also corroborated in visual experiments in which we had absolute control of the stimulus.

\section{Periodic Change: A. Hour-uaves.}

The most salient feature in the records, especially with reference to the height of the threshold, is a periodicity. The records agree in showing at least two sets of rhythmical fluctuations; and, in addition to these, there enters the well known attention wave, which practically coincides with the individual acts and therefore does not appear as a wave in the record. For convenience, we may designate the three sets of waves, respectively, as

1. The hour-waves (20 to 200 minutes).

2. The minute-waves ( $1 / 2$ to 20 minutes).

3. The second-waves (a few seconds).

The hour-wave can be seen most clearly by following the main zigzag lines showing the averages by tens. In some records two sets of hour-waves are discernible. For convenience we may call them the large and the small. The dividing line between the two groups is arbitrary and may be taken at about thirty or forty minutes.

In order to show approximately the number and length of the hour-waves a diagrammatic table, Table I., is given showing the upper and lower points, the crest and the basin, of each wave. The numbers denote the time, counting in minutes from the beginning of the test, and they are placed in an upper or a lower line according as they represent high or low points in the waves. The wave-length is proportional to the horizontal distance between the numbers, but differences in height are not 
TABLE I.

Periods of The HoUR-waves in Figs. I. TO $\mathrm{X}$.

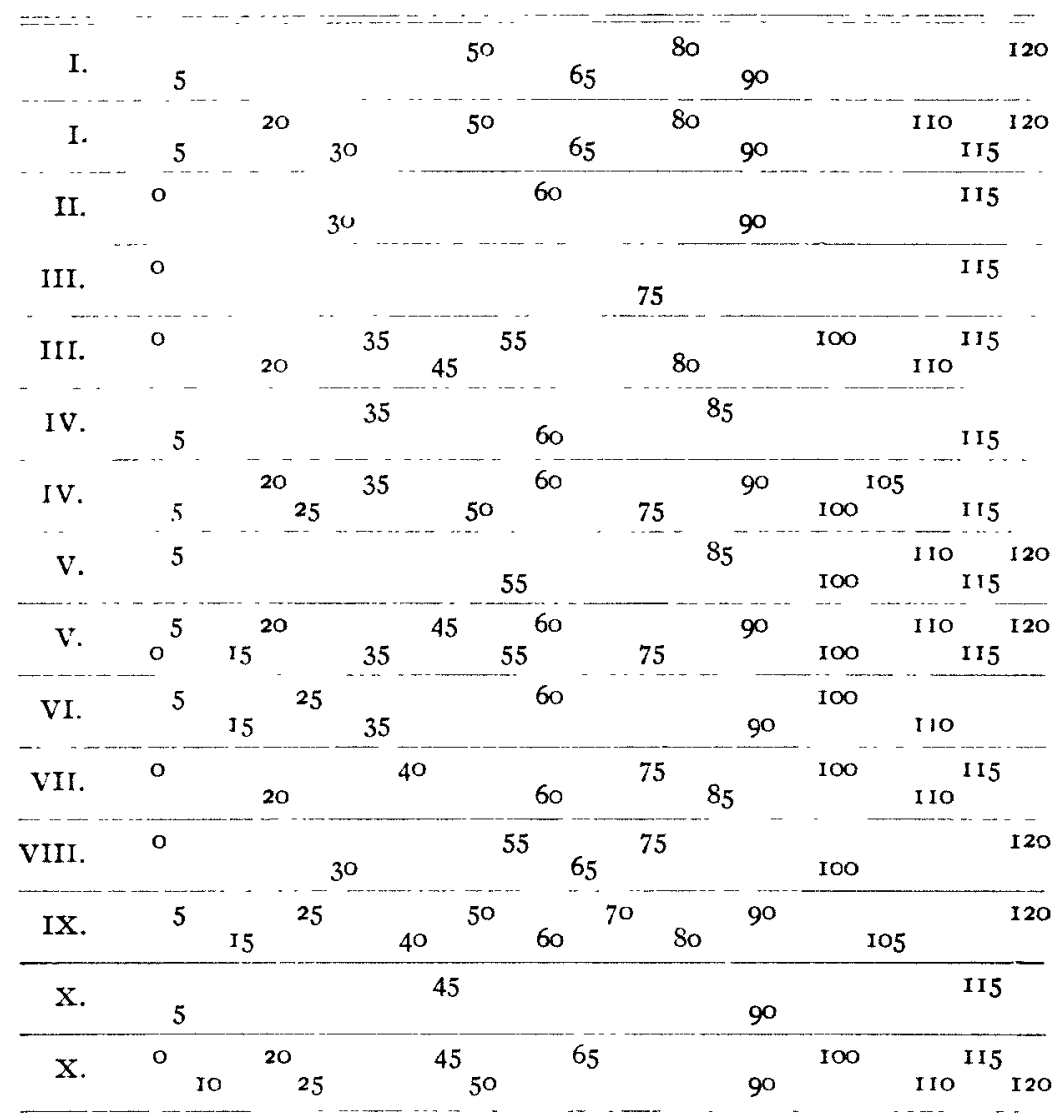

shown. In these estimates, To is taken as the principal guide because it is a more reliable index. to the moment of perception than $T u$; the appearance of a sound can be determined more definitely than its disappearance.

The estimates in this table are, of course, somewhat arbitrary. In many cases there is latitude for differences in interpretation. The table represents the estimates upon which the writers have agreed. In five records, (I., III., IV., V., and X.) large and small hour-waves are discernible in more or less distinct sets, as indicated in the table. II. and VIII. might also 
have been divided into short waves, but these waves are not very distinct.

The waves vary not only in length but also in form. While the general tendency is an approximation to the sine curve, this form suffers all sorts of distortion. On the assumption that there are two or more sets of waves, one can readily see the effect of interference and reinforcement. But many sporadic variations seem to be due to aperiodic influences.

One very expressive feature is that there is a tendency for the hour-wave to be shorter in the latter half of the record than in the first. This may be seen on a glance at Table I. Where there are two sets of hour-waves there is a tendency for the two to coincide near the end. Compare the two sets of waves, $e . g$. , in Record I., Table I.

One might suppose that every record should begin with a high crest, but there is no constant tendency in that direction.

\section{Periodic Changes: B. Minute-zvaves.}

We have spoken of the main curves as zigzags. These zigzags bring out the minute-waves. In order to show these short waves more clearly than they are shown in the curves of averages, a section of the $T o$ from each of the ten curves is represented in detail (Pl. II.). All these sections begin with the beginning of the second half hour of the record and include two hundred acts. This portion of the record is selected because it is perhaps freest from erratic variations, coming as it does after a period of adaptation and before the onset of discomfort.

Fig. I $a$, Pl. I., represents the whole To-record in this manner for Record I., to which it runs parallel. It shows how the minute-waves enter as partials in the hour-waves.

The tendency toward periodicity is unmistakable, but the waves are not homogeneous, nor are they limited to one system. Here, as in the longer waves, different sets of tendencies are operative producing reinforcements, balances, or interferences. One wave appears as a partial in another and is itself made up of ripples. A minute-wave may be a partial in an hour-wave; there is a gradual transition from one to the other. 


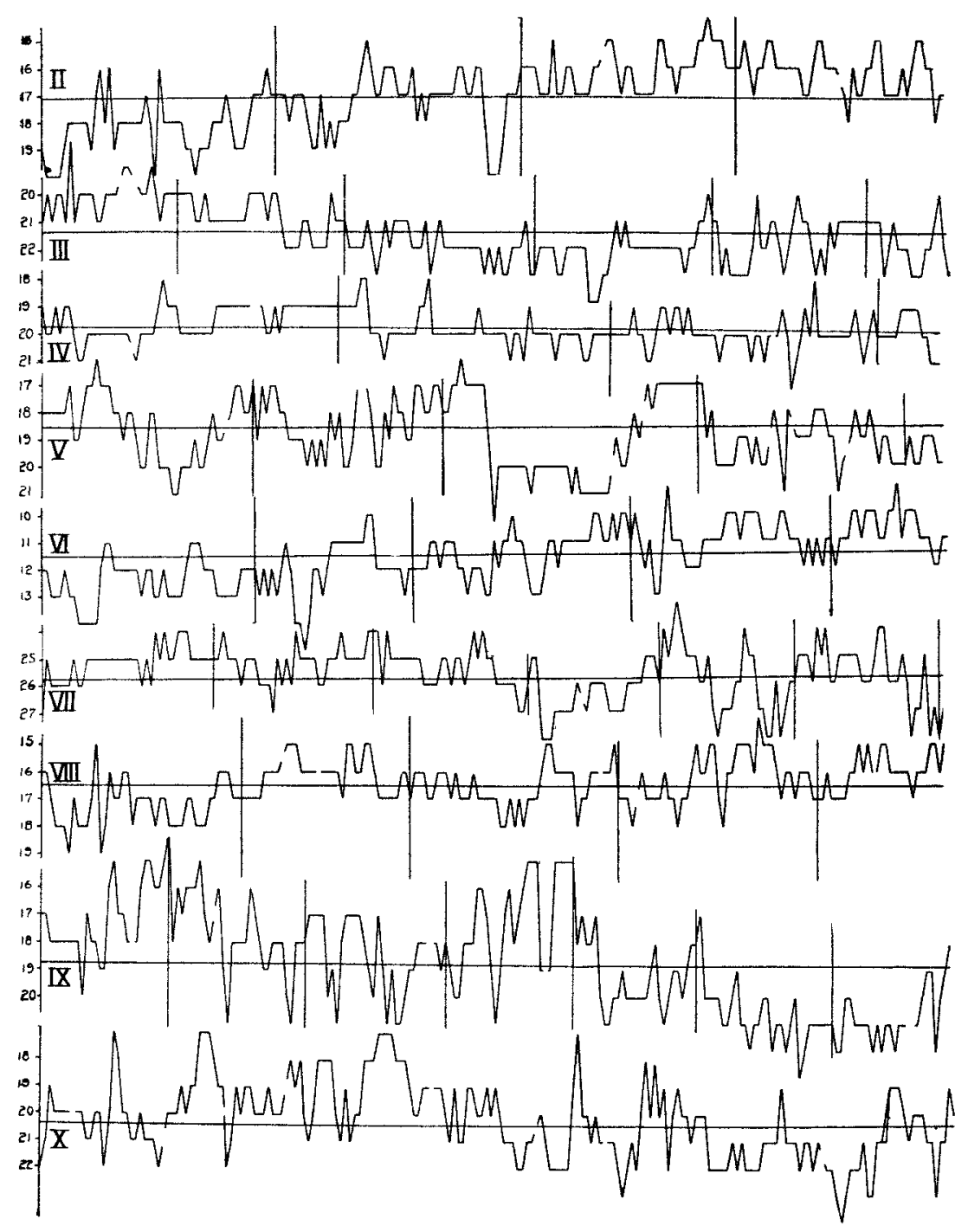

Plate II.

Periodic Change: C. Second-zvaves.

The attention-wave of Urbantschitsch ${ }^{1}$ plays an important rôle in this work. It is unnecessary to enumerate here the con-

${ }^{1} \mathrm{Med}$. Centralbl., $1875,628 \mathrm{ff}$. Good summary accounts are found in Titchener, Exp. Psych., 'Instr. Man'1, Qualitative,' $194 \mathrm{ff.}$, and in Wundt, Physiol. Psych., 5th ed., III., $366 \mathrm{ff}$. 
clusions of the valuable researches on that wave. We have assumed its existence and it remains to point out under what conditions it entered into the present process. We shall try to show that the attention-wave in this experiment is synonymous with, or rather, constitutes, what has been defined above as the second-wave.

The act which is the object of study in this series on sensibility, as defined on page 3 , forms a peculiar basis for the second-wave. Owing to the method employed in recording, these waves do not show in the records, but the known conditions and requirements and the introspective accounts furnish us satisfactory evidence of their existence.

The act may be regarded as the basis for one wave or for two, according to the point of view taken. According to the former, not only is the duration of each act approximately the length of an attention-wave, and its recurrence periodic, but the stimulus constitutes a wave in its intensity change - rising from an imperceptible stimulus, through the just perceptible, to the more than just perceptible, and then back, receding to the non-perceptible. Corresponding to this, there is a complete wave of consciousness, for, on account of associated inagery, the subliminal part of the wave is as concrete in consciousness as the supra-liminal part.

According to another point of view, the act readily divides itself into two complete and distinct movements of attention, the maxima of attention being just before $T o$ and $T u$, respectively, and the corresponding minima immediately after these points. The two waves in an act differ quite radically in character, but they both serve the same purpose, namely, rest through relaxation of attention. A moment of relaxation followed the perception indicated by $T o$ because the sound grew relatively strong during the united reaction-time of the observer and the experimenter; and, the approximate duration of this intensity was known from the preliminary practice. Then a moment of relaxation followed the perception indicated by $T u$, from the conviction that the sound had gone below the threshold and there would be a certain appreciable time before it could return. Thus, in one case the attention relaxed for a moment because 
the sound was so strong that it could be heard with ease, and in the other because the observer assumed that, for the moment, it was inaudible. Similarly the knowledge of the periodicity in the stimulus enabled the observer to concentrate attention at the probable appearance of the thresholds $T o$ and $T u$.

In order to compare the work in which the second-wave is merely subjective with that in which it is also objective, Observer III. took a special test. The same apparatus was used as before but, instead of a sound varying about the threshold by actual change in intensity, the stimulus consisted of a liminal sound of constant intensity, and the observer recorded the subjective fluctuations by holding the key down while the sound was heard and free while the sound was not heard. In order to minimize the tendency to hallucination, a one-fifth second interrupter was substituted for the fork. A graphic record was taken by means of the multiple recorder. ${ }^{1}$

The experiment covered a period of two hours. From the facts learned in the foregoing experiments, it was evident that one intensity of sound would not remain liminal throughout that long period. Therefore we adopted the arbitrary method of raising or lowering the intensity of the sound by one step on the audiometer when the sound had been heard or not heard, respectively, for a continuous period of thirty seconds.

The experiment was made $3: I_{7}$ to $5: 17$ p. m., April I4, 'O4. The introspective account follows:

I was in fairly good condition for afternoon work. Thought that probably I had remained at the same standard all the time because I was not aware of having had any periods long enough to call for the change. The subjective standard was retained satisfactorily throughout.

The wave seems to be dependent upon voluntary effort to a large extent. At times I would feel, "now I have held it so long that I must give up in order to be able to continue.' Very many of the fluctuations are due to slight disturbances, both subjective and objective. The tendency to fall into an automatic rhythm is especially dangerous. For these reasons I do not place much significance upon the length of the waves. Yet the objective disturbances were only such as we notice when ordinary disturbances are excluded, and the rhythm is in part really what we seek.

1 The recorder is described in Univ. of Iowa Stud. in Psych., 1901, III., $I-I 6$, as a part of the psychergograph. In its present form, fountain pens are used in place of the lead pencils, and an electric motor is used instead of the clock-work. 
The heard sound varied within wide limits; at times it seemed as much as five points stronger than the barely perceptible, and I was able to notice distinct wavelike rises and falls in intensity. This experiment is more taxing on attention than the other experiments (Series I.).

Let us first observe the bearing of this special experiment upon the interpretation of the second-wave in the main experiment. Fig. I I shows the numerical distribution of the different lengths of the attention-waves - the solid line for 'sound heard' and the dotted line for ' sound not heard.' The length is represented in seconds on the base-line and the vertical scale shows the number of cases at each level. The period for which the sound is heard most frequently is 6 seconds, and the period of greatest frequency for the sound not heard is 3 seconds. The curve rises at 30 because that point includes all that would

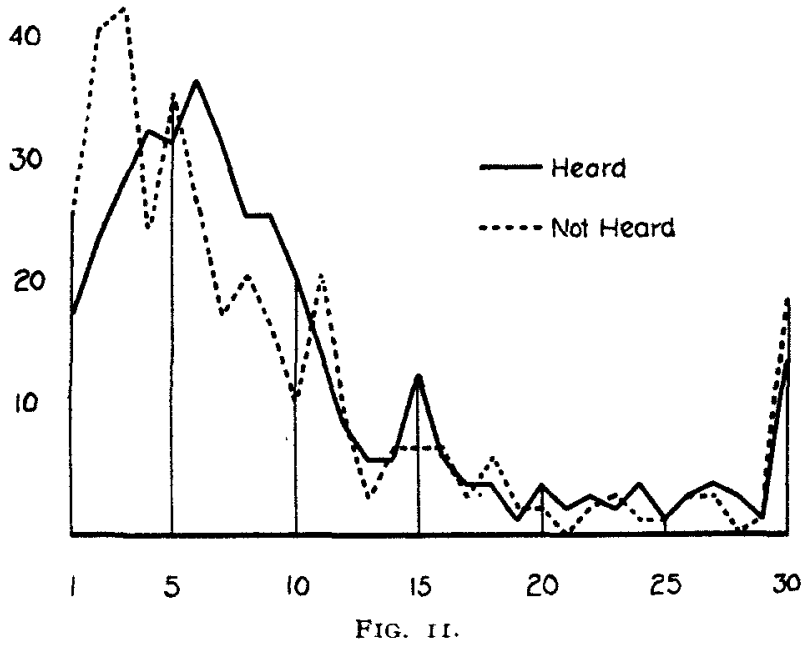

have been longer than 30 seconds if the standard had not been changed at that mark.

The most frequent length of the complete attention-wave in the special experiment is, therefore, about 9 seconds. The average duration of a complete act in the main experiment upon this observer (see Fig. III. in Plates I., II., and III.) was 8.4 seconds. That is, the typical attention-wave, purely subjective, coincides well with the objective wave in an act. In a way, the periods of supra-liminal sound correspond in the two experiments, so 
that we may say with reference to both that the sound was heard during the attention-wave and not heard during the inattention wave, provided we count the threshold transition periods with the former.

This wave which coincides with the act is a wave of secondary passive (Titchener) attention.' Within it, we find two distinct waves of active attention. Such is the case both in the experiments in this series and in the classical experiments upon the attention-wave.

Since the average length of the act was 8.4 seconds for Obs. III., the length of each active attention-wave was about half of that, or 4.2 seconds, in accordance with the conditions of the experiment. It is safe to estimate that the period of effort occupied about 3 seconds out of the total, and the period of absence of effort the remaining 1.2 seconds.

The interpretation of the combination of the two forms of attention may be illustrated by the schematic diagram, Fig. I 2 . The scheme applies both to the special act in this series where there is an objective basis for the rhythm and to the familiar attention-wave where the rhythm is purely subjective. We shall apply the scheme to the former first.

The dotted line $A B C$ represents the change in the intensity of the stimulus, and the horizontal base-line the mean threshold value of the stimulus. Then $T o$ falls at $A$ and $C$, and $T u$ at $B$. The curve $D E F$ represents the form of distribution of the secondary passive attention, the part above the base-line indicating presence of this form of attention and the part below, absence. The curves $G H I$ and $I J R$ represent the form of distribution of the active attention-waves. ${ }^{2}$

The figure thus throws into clear perspective the result of the analysis of the complete attention-wave into its two component elements and suggests the general outline of the resultant of the two. There is a state of attention from $G$ to $E$, but it differs in kind and strength, and the wave is not smooth, as

${ }^{1}$ For brevity, it will be spoken of hereafter as the passive, with the understanding that the secondary passive is meant.

${ }^{2}$ To coincide with the act as described in the main experiment, this diagram should really begin at $I$ and make a complete cycle from that point instead of from $G$. No account is taken of the difference in the level of $T o$ and $T u$. 
has been supposed; it has three distinct prominences. The crests of the waves $G H$ and $I J$ are the result of special effort, while the longer crest in $D E$ represents no effort and yet a state of clear attention. But the three elevations are parts of a single phase of a long wave $G E$, because the attention is continuous during that period.

The period of inattention is short - only from $E$ to $R$. But the period of absence of active attention does not coincide with the period of passive attention; they change off in part, as it were. The former runs from $J$ to $R$ and the latter from $E$ to

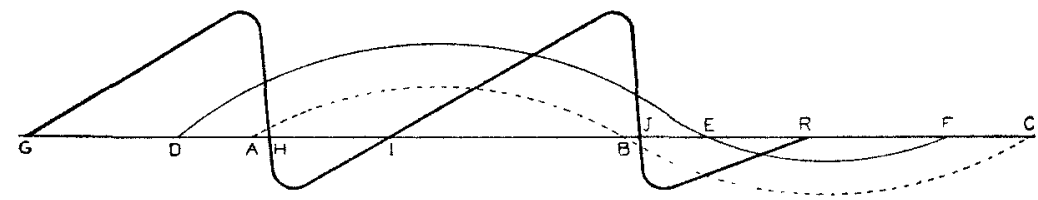

F1G. 12.

$F$. Therefore the rest from attention is not of uniform nature, any more than the attention was of uniform nature. From $B$ to $C$ no sound is heard; from $J$ to $E$ there is complete rest as regards active attention, but the passive lags; from $E$ to $R$ is a period of complete inattention; and from $R$ to $F$ only the passive attention is absent. Of course, the significance of these differences below the threshold must be interpreted in terms of the subconscious states.

Now, as has been suggested, the same analysis applies in a general way to the subjective attention-wave. To apply the scheme, we need to omit only the dotted curve, which represents change in the stimulus, and suppose that the stimulus is constant. The combination of the active and the passive attention-wave follows the same principle here as where the change is objective. It is easy to observe in the attention-wave experiment how the effort is exerted only at the point of coming in and the point of going out of the sensation; between these points the sensation holds the sway of consciousness and the clearness of the sensation during the middle period is in no way proportional to the effort of attention.

Have we not here discovered one of the secrets of endurance, a principle of economy and efficiency which applies to 
all mental activity? Are not the two experiments here discussed - the one in which the change is objective and the one in which the change is only subjective - fundmental types of attentive consciousness? This most elementary periodicity is not peculiar to continuous work under pressure. It is a characteristic of the ordinary mental activity even if there be only a single act of a few seconds duration.

Observe its working in simple observation, sensory or logical pursuit, constructive imagination, reasoning, etc. - processes which require attention. Frequently, however, only the $T o$ period is present, there being no demand for $T u$. Thus, in noticing whether a certain sensory stimulus is or is not present, there is a most effective spurt of active attention until we become aware of it (if it is perceivable) but, after that, it remains in consciousness for a moment although there may be no need of it, and there has been no objective strengthening of the stimulus. This is true not only of liminal stimuli but of stimuli of any strength which need to be selected by an effort of attention. The effort which lands the impression in consciousness is momentary and intense but the continuation of the impression in consciousness in its original, or even increasing clearness, is due to an after-beat, a pulsation of the secondary passive attention-wave.

The longer waves in this special experiment also deserve a passing notice. Fig. I3 represents the changes made in the standard during the two-hour period according to the prearrangement mentioned above. It is a crude way of representing the minute-waves and the hour-waves. The numbers at the left refer to the audiometer scale; and those at the base denote the time in minutes. A comparison of this figure with Fig. III. in Pl. I. and III. reveals a striking agreement of the two records. It is especially noticeable in the long hour-wave which starts with a high crest and then spreads over a long basin and finally rises again. This demonstration of the hour-waves proves that they are not peculiar to the kind of work done in the main experiment. 


\section{Progressize Change.}

Next to the periodic change in these records, our interest centers on the question of progressive change. For the purpose of demonstrating any progressive tendencies which may be present in the record as a whole, the results of the two halves of each record are arranged for comparison in Table II.

The first column shows the average $T o$ for the first half of each record, and the second shows the average mean variation of these on the basis of groups of ten. The third and fourth columns show the same for $T u$. The fifth shows the width of the threshold - To minus $T u$. The next five columns contain the corresponding facts for the second half. The eleventh and the twelfth columns give the differences between the two halves, the plus sign indicating loss and the minus sign gain in sensibility. The thirteenth column shows the difference in the width of the threshold for the two halves. The fourteenth shows the range of variation in $T o, i$. e., the difference between the highest and the lowest points in a record on the basis of one hundred acts as a unit. The fifteenth column shows the range of variation in the width of the threshold on the same basis.

In respect to sensibility, or height of the threshold (Col's II, I2), the records may be divided into three classes : those which indicate gain (I., II., IV.); those which indicate loss (VI., VII., VIII., IX.); and, those which indicate no decided gain or loss in sensibility (V., X.). For fuller interpretation, the form of each curve should be taken into consideration. In Record III., $c . g$. , there is a progressive loss during the first two thirds of the period and a gain in the last third. It is certain that there is no general tendency in favor of loss or gain. The .5 (Col. II) balance in favor

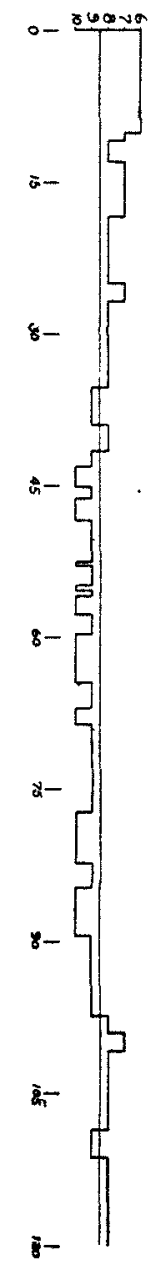

FIG. 13. of loss in $T o$ is only twelve per cent. of the range of variation in To (Col. I5) and is negligible; the corresponding balance in $T u$ is only .I. To what extent we may regard the records as revealing types of observers, remains to be demonstrated. 
TABLE II.

COMPaRison OF THE First and THE SECOND HaLF.

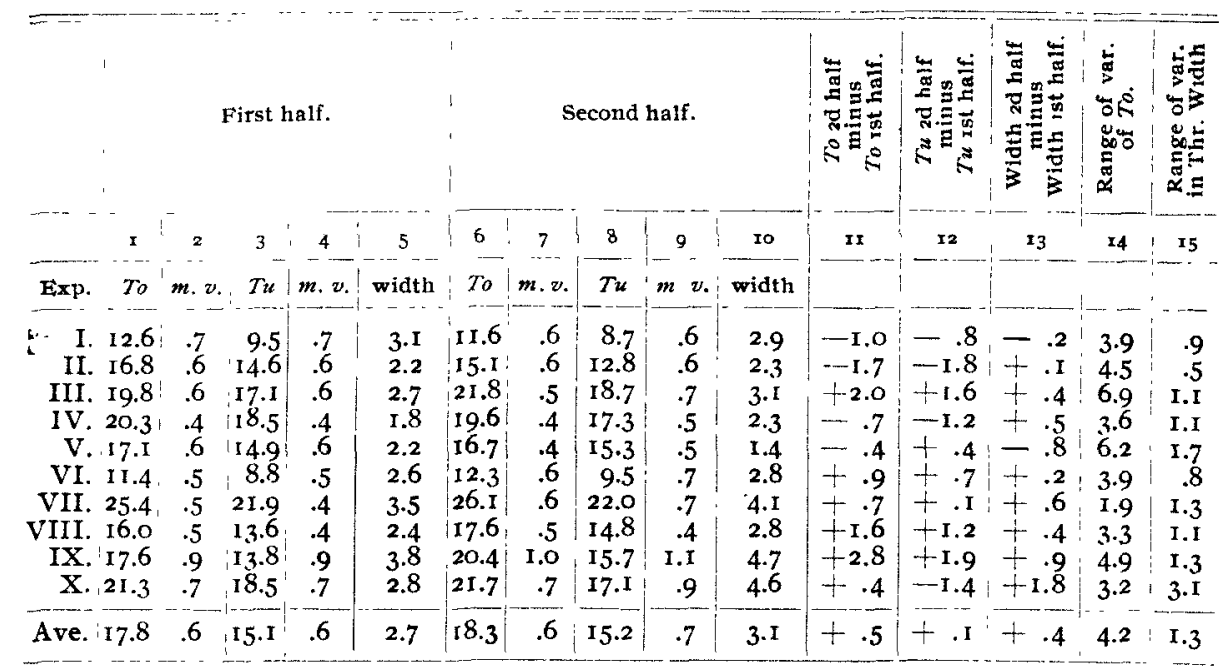

In respect to mean variation there is still less evidence of progressive change (Col's 2, 7; 4, 9). In Records I. and V., the mean variation is slightly smaller in the second half than in the first, $i . e$., the records tend to improve in regularity; and, in Records IV., VII. and IX., it is larger in the second half, but in no case is the difference very great. In five records (I., III., VI., VIII., X.), and in the average for the ten records the mean variation is practically equal for the two halves.

There is a more decided progressive tendency in respect to the width of the threshold. Eight records show an increase in width in the second half as compared with the first (Col's 5 , ro, I3), and the average increase is .4 , which is thirty-one per cent. of the average variation in width (Col. I5). In the two records which show a decrease in width, the change is very small in Record I. and, in Record V., it is partially explained by the introspective record. ${ }^{1}$

\footnotetext{
${ }^{1}$ According to the introspective account the exceptionally large increase of width in Record $\mathrm{X}$. is accounted for in part as due to a change of standard of certainty. The uniformity in Record II. is due in part to a conscious effort to avoid the widening of the threshold.
} 


\section{Correlation of Changes.}

In retrospect, we may review the three kinds of changes with reference to periodic changes, progressive changes, and the correlations of the three factors, by means of the juxtapositions drawn in bold outline in PI. III. and the table of correlations, Table III.

P1. III. contains outline reproductions of the ten records. The curves are drawn on the basis of averages for one hundred acts for each point and represent To, m. v., and threshold width. For the present purpose, $T u$ would be similar to $T_{o}$ which is used. The $m . v$. here used is the mean between the

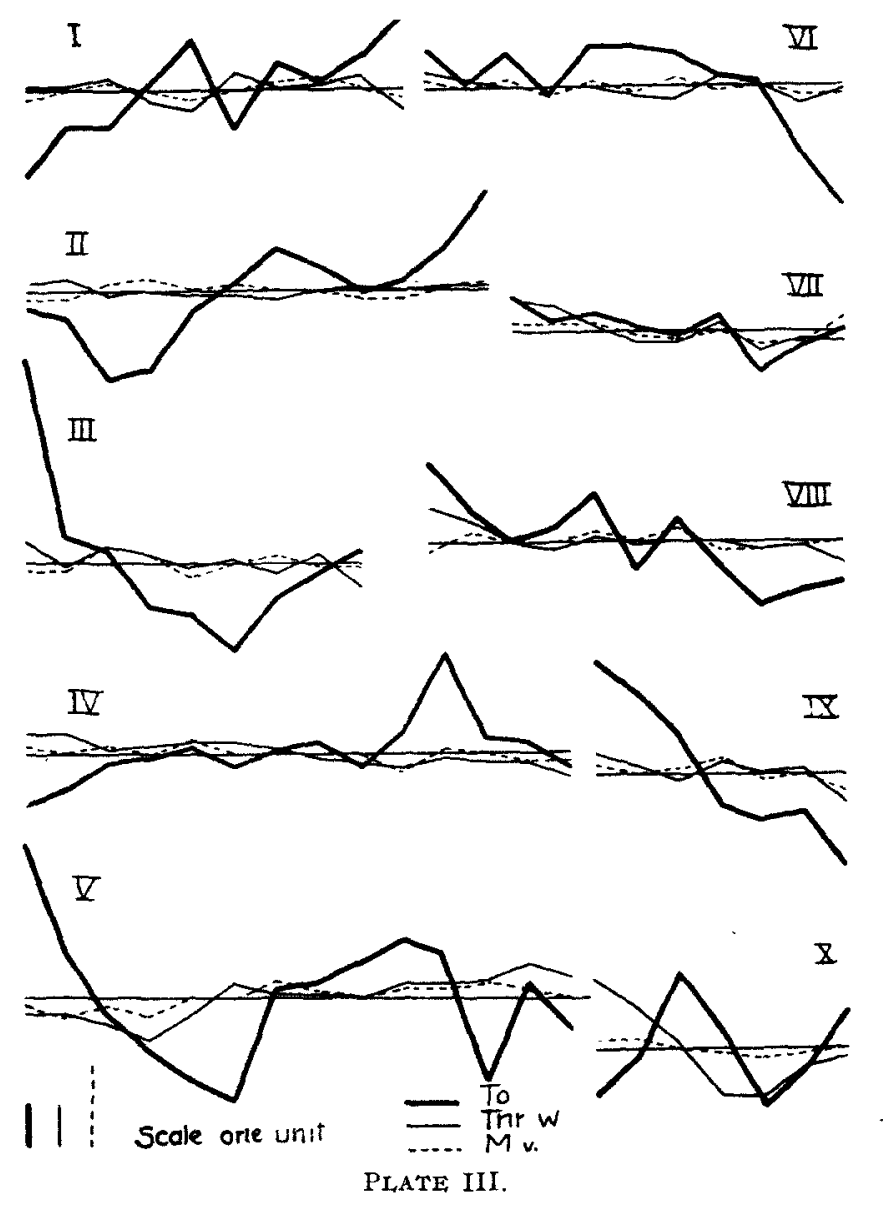


average mean variation for $T o$ and the average mean variation for $T u$. The ordinate scale is twice as large for the $m . v$. as for the other two curves. The horizontal line is a common base and represents the averages of the respective factors for the whole record.

The same data on which the figures in Pl. III. are based are treated by Pearson's formula of correlations. The results are presented in Table III.

For the purpose of this correlation, a point $-i . e$. , the average of one hundred acts, following the grouping indicated by the heavy horizontal bars in Pl. I. - is considered high or low as follows: for $T o$, a point lying above the average for the whole record - $i . e$., indicated by a smaller number than the average in the record of hearing - is considered high ; for $m . v$., a point represented by a smaller number than the average for the whole record is considered high; and, for threshold width, a threshold narrower than the average is considered high. Agreement of high with high, or low with low points is represented by the plus sign; disagreement by the minus sign. $n$ denotes the number of points considered.

Table III.

CORRELATIONS OF $T o, m . v$, AND Threshold Width.

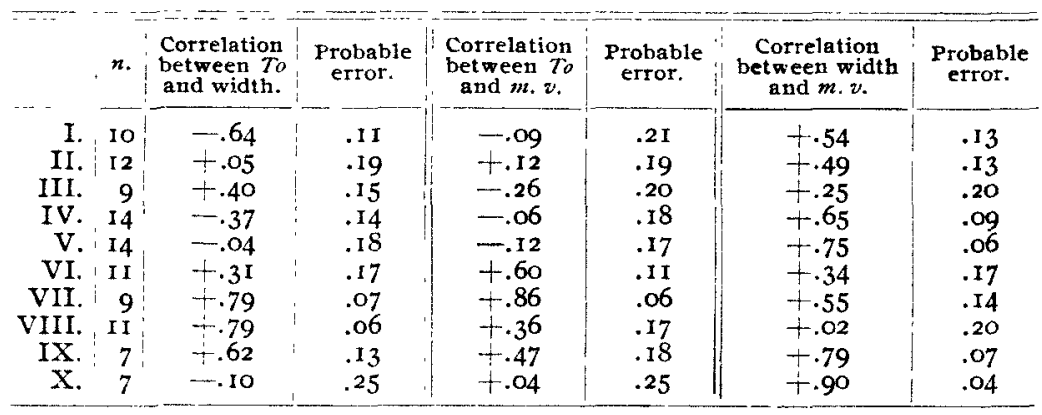

The column for To and threshold width shows six positive and four negative cases. This does not prove that no correlation exists, but rather points to the existence of radically different types of method in working. This view is borne out by intimate knowledge of the conditions of the experiment and by the introspective observations. 
The columns for $T o$ and $m$. $v$. show a similar divergence, although there is a stronger preponderance in favor of a positive correlation.

There is a strong correlation between the $m . v$. and the threshold width. This probably means that $m . v$. (variability) and width (alertness) are signs of the same general central efficiency. If the $T o$ (sensibility), had remained constant in the record of a period, the decline in the central process would indicate that there was an increase in the peripheral efficiency. But in view of the conflicting types of the records we dare not draw the conclusion that there is a progressive increase in peripheral sensitiveness.

\section{'Before'- and 'After'-Tests.}

The before- and after-tests were intended to show what effect, if any, the long test had upon the ear not used. A marked change in the relation of the sensibility of the two ears would indicate that a peripheral change had taken place in the ear used.

TABLE IV.

THE 'AFTER'- AND THE 'BEFORE'.TESTS.

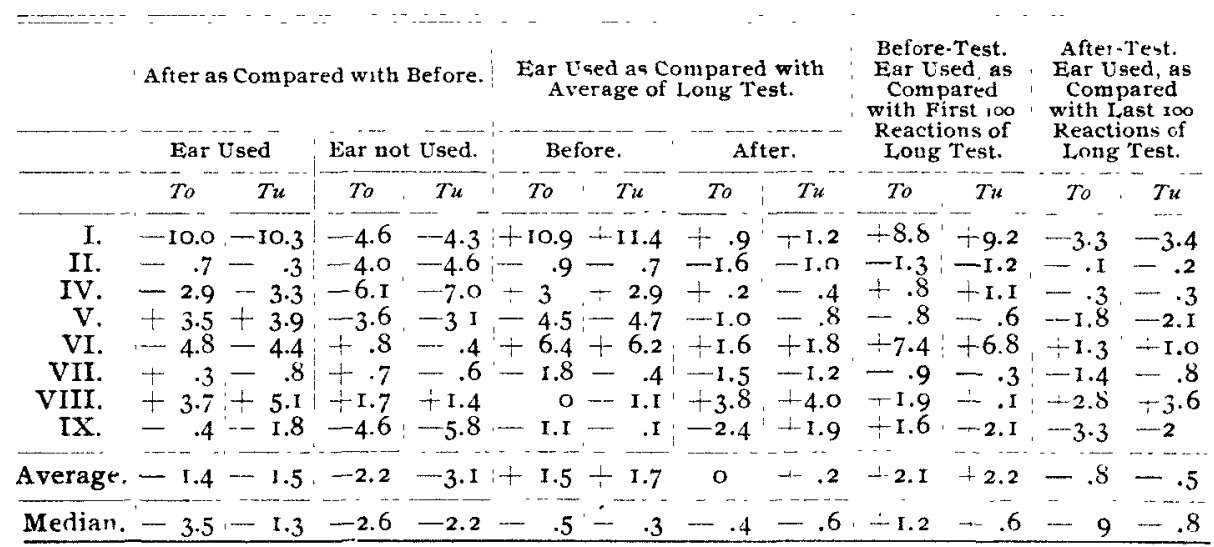

To supplement the graphic records in P1. I., the significant features of the results are exhibited in Table IV. Here a minus sign indicates 'keener sensibility' and a plus sign the opposite.

The after-test as compared with the before-test shows a gain in sensibility, if we consider the average or the median for 
the eight records, and the gain is practically equal for the two ears. But, in view of the radical divergences in the records, very little significance can be attached to the average or median.

The average and median for the ear used as compared with the average of the long test show an approximately equal distribution above and below that average, both in the before- and the after-tests, although the deviations on both sides are large.

There is a closer agreement between the end-tests and the respective adjacent ends of the long record; there is a slight tendency for the before-tests to be inferior to the first hundred acts of the long record, and for the after-test to be slightly superior to the last one hundred acts in the long record. This shows how the sensibility in the end-tests depends upon what portion of the hour-wave such a test is taken in.

There are special explanations for some of these divergencies. The receiver was not tied on, but was held to the ear by the hand, and slight changes in the adjustment would cause differences in the intensity of the sound. The pain from continued pressure may have influenced some observers in the adjustment of the receiver for the after-test. The subjective conditions of the end-tests as compared with the main experiment, and of the end-tests as compared with each other, seemed to influence different individuals in different ways. Thus, in the before-tests, the initial impetus of volition came in to the greatest advantage; in the main experiment, the calm adaptation to a uniform act was effective; and, in the after-test, the heightened irritability and the sense of opportunity for a final spurt played significant rôles. We had hoped to eliminate these and many similar sources of error by taking the test on both ears, both at the beginning and the end, and by making the end-tests of the same nature as the main experiment. But the data obtained are significant chiefly in pointing to individual differences and complexities of conditions. Three ${ }^{1}$ of the records (I., VI., VIII.) show a decidedly greater gain in the ear used, one (VII.) shows neither gain nor loss in either ear, and four

${ }^{1}$ To these may be added a fourth, taken on Observer III., but not included in the table because it was taken under somewhat different conditions. 
(II., IV., V., IX.) show a decidedly greater gain in the ear not used.

\section{Introspective Accounts.}

A general view of the experiences in a period, especially the difficulties and sources of error, may be obtained in part from the introspective accounts. In the following extracts from the accounts which were written by the observer immediately after the experiment, the language of the observer is used, but irrelevant material is cut out and much is abridged.

I. (D. S.) Io:25 a. m., April 16, 'O4.

The only disturbances that were noticed in this experiment were due to my changing position on the chair. $* * *$ This occurred three or four times. It is my impression that the threshold was about the same at the end of the record as at the beginning, for the reason that $I$ felt scarcely any fatigue from the work. There were places about the middle of the record where there was a tendency to become.inattentive and sleepy. There was also a strong tendency throughout the entire period to react rhythmically.

II. (G. H. K.) 9:54 a. m., April 21, 'o4.

The observing-room was cold, owing to a mistake in the ventilating. A subjective sound was heard all the time, especially at first; this was very confusing. I expect to find great irregularities in the record. The duration of the sound varied greatly. There were several drowsy periods during which there was a tendency to fall into rhythmic action. The time seemed long. During the last half hour I felt much discouraged. I had visual imagery of what was going on in the recording-room. My imagination was very active the whole time.

III. (C. E. S.) 9:54 a. m., April 12, 'o4.

Only light work before the experiment. Air good, and a good day in general. The only discomfort I suffered was in holding the receiver. It should be tied on both to avoid fatigue and to secure constant adjustment. Slight movements of the receiver cause both qualitative and intensive changes in the sound.

I suffered no serious mental strain, still I found that I held my mouth open all the time so that my throat felt parched at the end of the experiment. I did not have any sleepy spell. There was nothing particularly wearying in the process. The quiet and darkness of the room are so sootbing, the stimuli are so delicate and graceful, and the feelings of expectancy are so generally satisfied that $I$ experienced an agreeable complaceny and comfortable adaptation as the experiment progressed. I did not get tired and felt no relief from the change at the end.

The duration of the sound seems to fit my attention-wave nicely. The gradual rise and fall of intensity led me to image a combined auditory, visual, and motor-wave which was decidedly pleasing and had great carrying power. Any interruption in this wave was disturbing, but such disturbances sometimes served to make me more alert. There was a tendency for me to shorten the period in the rhythm and 'rush' the experimenter, and I had to break away from that periodically. 
The experiment is conducive to mind-wandering. The noticing of the To takes but a small fraction of the time and then one soon learns to estimate the time for the $T u$ from the strength of the sound immediately after the response to the To so that there is a freedom from suspense which really should be present.

IV. (C. P. S.) I :32 p. m., April 26, 'o4.

(The account of this observer gives a vivid description of the characteristic experience during a period, and is, therefore, inserted in full)

My physical condition was not of the best, for a severe cold made it impossible for me to breathe through my nose, consequently the whole of the mucous membrane of my mouth and throat became exceedingly dry and parched, necessitating a considerable degree of effort and swallowing to moisten it. Invariably these muscular efforts of my throat and tongue made my sense of hearing seem very much less keen, and on nearly all occasions I was compelled to give the 'objective' signal. This condition was to be noticed more during what might be judged to be the first half of the period than during the latter half; but was nevertheless a frequent factor to be dealt with.

The first portion of the period seemed on account of its novelty and my comfortable position to pass rapidly, and to be full of interest. My attention turned naturally to the experiment in hand, and I felt that I was making a splendid record, for the intervals between my responses were very short. However, as the comfort of my position decreased, and the necessity for changing the position of my limbs and body grew, my attention waned also, until I was suddenly called back to the matter in hand by what seemed an unusually loud and prolonged sound in the receiver. I felt such a time to be proper for a change in position, which I made, at the same time giving the signal. Immediately thereafter I again became conscious of a greater degree of attention.

During about the middle portion of the period, and again later, an element of disturbance arose; namely, the penetration of sound caused by someone walking in the nearby corridor. This distracted me considerably and I gave the objective signal, after which my degree of attention again increased.

A desire to leave my position and stretch body and limbs became almost irresistable during the latter portion of the period; but the belief that the period might be nearly over kept me to my task. A further desire to know how much time had passed returned repeatedly ; but this was thrust away by the argument that if I turned on the light and consulted my watch, my attention wonld be completely distracted, if for only a moment, and the validity of the experiment impaired. This train of thought and the first desire mentioned both contributed to my lack of success in quickly discriminating between silence and sound.

A frequent desire for deep inhalations of breadth, something like yawning came over me, and my yielding to the desire was the cause for several of my signals.

One thing I noticed at intervals throughout the experiment was the loud and violent beating of my heart. This usually followed some change of position and was quite a disturbance. I was most conscious of it when giving almost breathless attention to the receiver. Pulsation of the blood in my temples was also almost sufficient to drown the fainter sounds in the receiver.

Toward the end of the experiment I became conscious of a considerable pressure, almost equal to pain, in the pinna of my ear, caused by the receiver. 
At one time a train of thought about my foot-racing started in my mind and $I$ experienced the same violent throbbing of the heart and tingling of the nerves which I experienced just before every athletic contest. This was another source of disturbance, but concentration of attention was sufficient to cause it to disappear as quickly as it came.

The long sound in the receiver which indicated the end of the experiment proper caught me in a perfectly passive condition, responding automatically to the stimuli. I received it, however, with considerable relief, and yet with a certain reluctance for which I canuot account.

So far as I can tell, there was no difference in the preliminary test in the hearing ability of either ear. In the final test I noticed no difference in the relative hearing ability of the left ear as compared with the preliminary test or as compared with the experiment proper. When testing the right ear, however, the first few tests were very poor on account of an improper adjustment of the receicer. With the assistance of the left hand I then held this in a better position, responding with the right hand. The strain of the awkward position of the left arm made me very attentive to it as well as to the receiver which it supported; and I found my hearing ability in this ear so far as I could tell, to be better than that of the left.

When the experiment was over I felt as though I had just finished a period of severe study. No great degree of physical fatigue was noticeable. At no period during the experiment was I able to judge of the amount of time which had passed.

During the first part of the period I sat with my eyes wide open staring into the dark. Many flashes of colored light were visible. Later I sat with my eyes shut because of fatigue in my eyc-lids and the distraction caused by winking. With my eyes closed $I$ also observed the many colored lights.

V. (M. B. C.) 9:35 a. m., April 15, 'o4.

I was in good physical condition. The period was quite free from disturbances, except such as came from slight changes in position. During the first third, I was conscious of my breathing and of both mental and phy sical straiv. During the second third I was conscious of fatigue of both mind and body, and of mind-wandering. Expected the experiment to end. During the last third there was a sudden sense of relaxation and ease, mentally and physically. With the exception of pain from the pressing receiver, this period was the most comfortable and I felt a keener interest in the test than before; but I was aware of making many mistakes. During the whole experiment $I$ had about five or six distinct cases of mind-wandering.

VI. (M. C.) $8: 42$ a. m., April I9, 'O4.

For the first fifteen minutes or half hour, the test seemed entirely pleasant and I seemed to be in a sort of a dream. This part of the record is probably best. After that my head began to ache on account of the baudage, aud that distracted my attention somewhat. During the entire test I could notice that my attention would be exerted in waves and it secmed that after a slight movement of the head the record would improve for a time. The headache made the test seem extremely long and tiresome. I began to anticipate the end of the test at what I should judge was about the middle of it. Eariy in the test, before it became unpleasant, I caught myself falling asleep although I did not 
seem to be drowsy. The quality of the sound seemed to change from time to time. There also seemed to be a difference in pitch and the higher sounds were much easier to hear.

VII. (R. E. K.) I :33 p. m., April 25, 'O4.

During the first half hour it was easy to keep the attention on the work and I think my keenness of perception was gradually increasing without any marked rise or fall. The next half hour was made up of irregular rises and falls, and it was harder to focus attention, due in part to the discomfort caused by the receiver and by the limitation of movements. It was easier to give attention to the work, after varying the position, e. g., from the erect position to leaning on the table. Gradually I became drowsy and 'came to' with a start thinking that $I$ bad neglected to respond; this tended to focus my attention upon the sound for a while. These periods were quite short and were followed by drowsiness. At about the beginning of the last half hour, or twenty minutes, I succeeded in rousing myself. I think the record was gradually growing better at the end of the experiment. I am sure that my threshold was lower at the end than at the beginning of the experiment. During the last half hour it was not difficult to give all my attention to the work; no thought was given to time as was the case in the middle of the experiment.

VIII. (O. H.) $9: 35$ a. m., April I8, 'o 4 .

During the first ten or fifteen minutes of the experiment, the pulse beat was perceptible in the head. Perhaps this was due to the band which held the receiver against the ear. About the end of the first twenty minutes I experienced, but only for a moment, a peculiar lack of sensibility or a numbness all over the body. The experiment seemed long. For a few minutes near the end of the experiment I was disturbed by continual swallowing of saliva. Part of the time the experiment seemed rhythmical. I felt weary from continuing in the same position.

IX. (C. G.) I :3I p. m., April 20, 'O4.

I was in good physical and mental condition. Felt sleepy about three times. Shifted the receiver twice because it hurt the ear, but do not think that that caused much disturbance. The time seemed long.

X. (A. W.) Io:I7 a. m., April 9, 'O4.

I found the sounds of my own body, breathing, etc., somewhat of a disturbance at first. It was often necessary to take a long breath to catch up. My arm and hand holding the receiver went to sleep. A queer feeling was also felt in the other hand. At first I think I gave the signal for the disappearance of the sound before such was really the case, because I was listening for a certain quality of sound. About twenty or twenty-five minutes before the close of the experiment I got very drowsy and was conscious of responding almost automatically, and here $I$ am sure that I listened for a certain sound-not merely sound - and signalled when this particular sound appeared and disappeared. After this I aroused myself and found that I could distinguish the beginning of sound which was much fainter than the 'certain' sound I had heard before.

The time seemed short, perhaps two-thirds as long as it actually was. I had a distinct feeling of aloneness when the sound ceased and a mental image 
of the sound was present all the time. Sometimes I pressed the key to keep out the sound, which was then more like a presence than a mere sound.

\section{Series II. Discrimination.}

\section{Problem, Apparatus, Method, and Observers.}

The same plan as was pursued in the study of sensibility in Series I. was here pursued in the study of discrimination. Experiments consisting of an uninterrupted series of determinations of the sensible discrimination were carried on for two-hour periods. The act remained uniform throughout, accessory conditions were kept as constant as possible, and the observer was expected to exert the maximum effort in attention to the act.

The act studied consisted in detcrmining whether the second of two consecutive sounds, which differed in intensity only, was stronger or weaker than the first. The same apparatus was used as in Series I. and the conditions of the observer were also similar. The threshold of hearing was first determined and then a point about ten units above that was made the standard. In minor details three different methods were used.

In the first two experiments, Records I. and II., the sound was started at the standard and sounded two seconds at this and at each successive point, the movement being either up or down, and the observer gave a signal as soon as he knew whether it was weaker or stronger than at the beginning. Two signal keys were used: pressing the right hand key indicated a stronger and, the left hand, a weaker sound. Immediately after the response the experimenter cut off the sound for an instant while sliding the carrier back to the standard. This interruption served as a signal for the beginning of the next act. An assistant recorded the responses and the amount of change required for each successive act of discrimination, as indicated by the audiometer.

The next three experiments, Records III., IV., V., differed from the first in the following respects. The sound was held at the standard approximately five seconds, instead of two as before, and the rate of change was not perfectly uniform because the experimenter did not use the metronome. The response was made by one key, one tap denoting stronger and two 
taps weaker. In experiments III. and V. a time signal was given to the observer every fifteen minutes.

The results of these five experiments are represented graphically in Plate IV., Fig's I. to V. As it turned out that more than half of the responses were made for a single step of change, it was found practicable to use the number of correct responses in a single step of change as a measure of the efficiency. Since nearly all the responses which were not made for one-step changes were made for two-step changes, the method reduces itself to the tabulation of the number of correct responses on the smaller step. But this makes it necessary to deal somewhat arbitrarily with the incorrect responses on that step. Since the chances were equal that a response would be right or wrong, one correct response was deducted from the total with every. error; thus, if there were eight correct responses and one wrong, the final record would read, 70 per cent. right. The zigzag line shows the average number of correct responses, on this basis, for each successive ten acts. The short horizontal lines denote averages for a hundred acts each. The long horizontal line shows the average for the whole record. The time is marked in minutes on the base-line.

Experiments VI. and VII. were made by the method of right and wrong cases. A metronome with relay was introduced into the circuit in such a way that the sound was cut out for a second every alternate second. Either the standard or a compared tone, perceptibly different in strength, could be sounded at the will of the experimenter; but it was agreed that the standard should never be sounded more than twice in succession and the compared sound not more than once at a time. The experimenter made the change by sliding the carrier while the sound was interrupted. ${ }^{1}$ The observer was required to signal every time the compared sound was heard.

The carrier on the audiometer (to show whether the standard or the compared sound was given), the metronome (to furnish a time-line and to indicate the duration of each sound) and the observer's signal key (to register the signal) were con-

${ }^{1}$ The difference was three steps on the audiometer in experiment VI., and two steps in experiment VII.; and the compared sound was weaker than the standard in the former and stronger in the latter. 


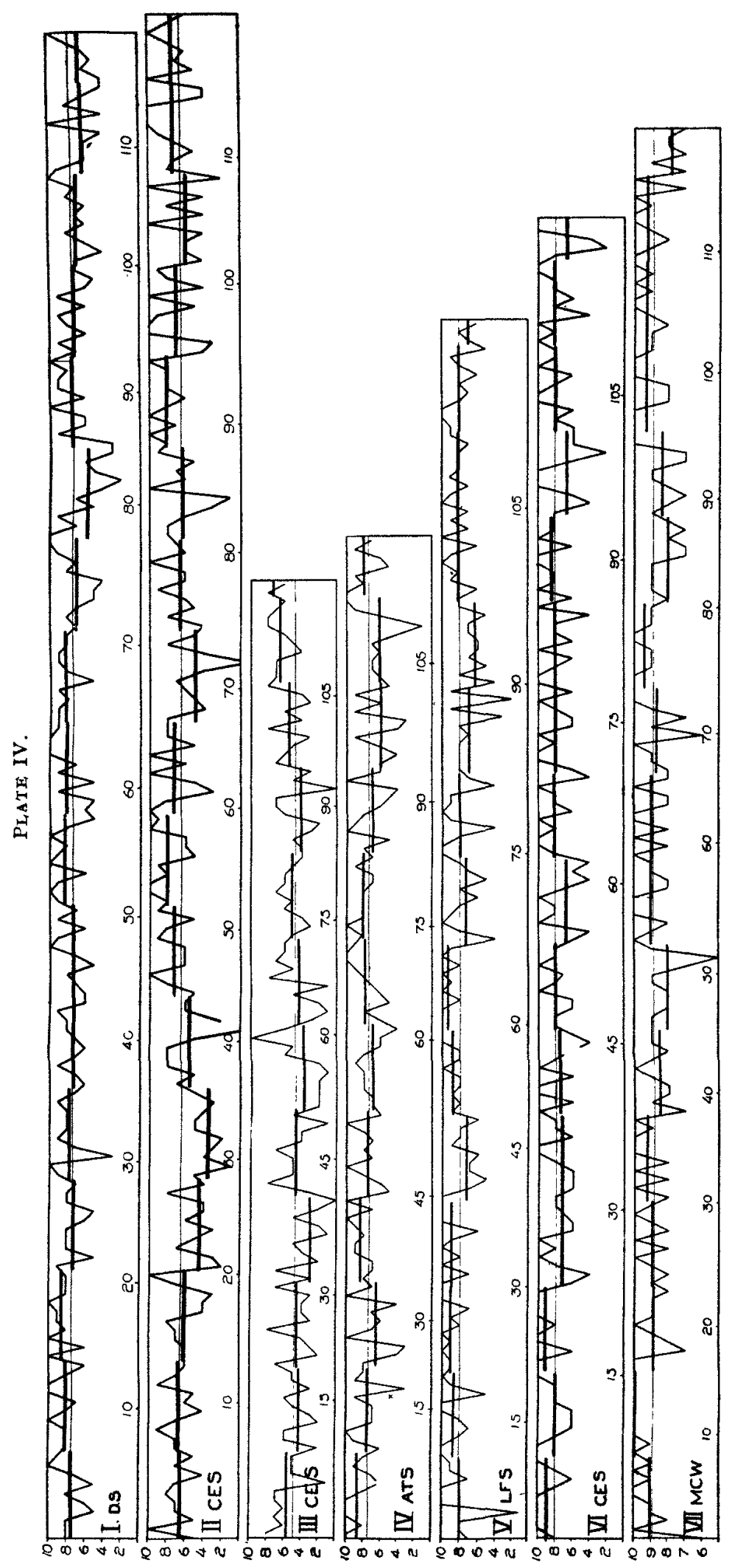


nected with corresponding pens in the multiple recorder ${ }^{1}$ by means of which a continuous tracing was obtained showing the correctness or error of each response, and, in case of errors, the nature of the error.

Two kinds of errors occurred : signals on the wrong sound, and failures to signal on the right. In counting points for the graphic record, the correct responses and these two kinds of errors were taken into consideration, but the errors were not differentiated. This method leaves out of count all those cases in which the standard was sounded and the signal properly withheld. The results of these two experiments are represented in Pl. IV., Fig's VI. and VII. The curves show the per cent. of correct responses on this basis. The range is from $5^{\circ}$ per cent. to roo per cent. The zigzag shows the grouping by tens and the short bars by hundreds, as before.

\section{Periodic Changes.}

The interpretation of these records is simple, after we are familiar with Series I. We look for periodic changes and progressive changes.

The hour-wave is prominent in all the records. Its general outline can be traced most readily by following the trend of the short horizontal lines, $i . e$, the averages by hundreds. In this series they appear both more distinct and more uniform than in the foregoing series.

Record III. shows a close agreement with records III. and XIII. on the same observer in the foregoing series, both in the long hour-wave of which there is only one phase, and in the shorter hour wave. These three records taken together indicate a characteristic individual wave series; but records II. and VI. which are on the same observer agree with these only in the shorter hour-wave.

The minute-waves are also very prominent and there is a striking similarity in the records. But the present method is not entirely adapted to bring out detail in these short waves.

Here, as in the foregoing series, there is a strong tendency for the second-wave to coincide with the individual act. The

ISee reference, p. 60 . 
time was suitable, and the new effort made at each beginning on the standard was conducive to the adjustment of the attentionwave to the duration of the act.

The distraction of introspection was avoided, as far as possible, in the regular experiment. But afterward, some experiments were repeated for the purpose of determining by introspection whether the combination of active and passive attention follows the same principle in the act of discrimination as in the act of simple perception.

We may illustrate the conclusion by reference to the simplest form of comparison in discrimination. In Fig. I4, let the dotted figures $A B$ and $C D$ represent two successive tones. The dura-

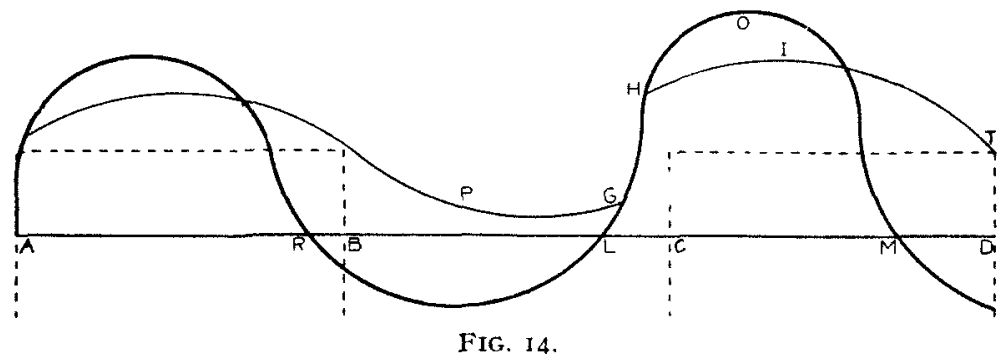

tion of each tone is one second and the interval between them is one second. The act consists in determining whether the two tones are equal or different in intensity.

The general form of the attention-wave in which the whole act is comprehended may be outlined by the composite curve $A N P O J .{ }^{1}$ But this may be reduced to its component elements; namely, the secondary passive wave $A P G H I J$, and the two active attention-waves $A N R$ and $L O M$. That is, the combination follows the same principle as was illustrated for sensibility in Fig. 12, p. 63: the act is performed largely by secondary passive attention, but at the critical points, short intensive waves of active attention occur.

This illustration presupposes a trained observer performing a familiar act under the conditions named. The proportions of the components would vary with observers and conditions, but

${ }^{1} N$ was cut out from the etching inadvertantly; it represents the first active attention-crest and is symmetrical with $O$. 
certain relative features are rather fundamental. (r) The two stimuli and the memory image of the former are grasped in a single wave of attention. (2) Active attention comes into prominence only at the critical moments. It does not cover more than the first part of each stimulus and the end of the memory image. (3) Both forms of attention rise higher for the last than for the first stimulus. There is also a wider scope of attention at the beginning of the second stimulus but this cannot be represented in the plane figure. (4) The early rise of the second active attention-wave is due to the effort to grasp the passing memory image and to take advantage of the sharp edge of the appearing stimulus. The rise of the passive wave at the same point is due in part to the feeling of suspense.

\section{Progressive Change.}

To determine the presence of progressive change roughly, the averages for the first and the second half of each record may be compared. Records II. and III. show a rise of 6 per cent. each, but in the latter the rise is accounted for approximately by the special impetus given for a final spurt by a time signal; and in the former, the absence of the usual high beginning for this observer is conspicuous. Five records show a decline in ability as indicated by the following per cents. respectively: I., 8 per cent. ; IV., 3 per cent. ; V., Io per cent. ; VI., I per cent. ; and VII., 2 per cent. On the whole, therefore, there is a tendency toward decline in ability in this period of work.

\section{Votes from the Introspective Accounts. ${ }^{1}$}

\section{I. (D. S.) $9: 30$ a. m., June 8, 'o4.}

I was in good condition for the test. Felt drowsy for three-fourths of an hour about the middle of the experiment. I also felt drowsy for a quarter of an hour after the experiment. The duration of the sound at the standard seemed to vary; this was disturbing.

III. (C. E. S.) 3 : Io p. m., June 4 , 'o3.

Good physical and mental condition. In the fourth quarter I had difficulty in keeping awake. Each quarter-hour signal aroused me to a keener discrimination. The signal gave a feeling of relief. I often moved slightly and the change of position broke the monotony. The absence of light was exceedingly soothing.

${ }^{1}$ Abridged as in Series I. 
There was no sense of increased fatigue during the second hour. In fact $I$ felt brighter in the second hour than in the first, especially in the approach to the end.

The errors are due to various reasons. Among the objective, the following may figure: the uncertainty of the tap on the key, movements of the receiver, and irregularities in the time of the stimulus. Among the subjective factors, are, mind-wandering, failure to remember the standard, and hesitation in reaction.

The observer felt no after-effect of the experiment until $9 \mathrm{p} . \mathrm{m}$. Then he felt an unusual pain above the eyes and a more decided feeling of general exhaustion than usual. There are no means of knowing whether these effects were or were not due to the experiment.

IV. (A. T. S.), $2: 45$ p. m., June 3, 'o3.

The period seemed short. I felt sleepy once and caught myself distinctly mind-wandering twice. I enjoyed the experiment and took special pleasure in the opportunity to do my best.

V. (L. F. S.), 3:35 p. m., June 3, 'o3.

I felt as if I had swayed backward and forward for fifteen seconds. In the last quarter, or half hour, I gritted my teeth as if I had been running an engine down grade. Do not feel tired.

VI. (C. E. S.), 2 :33 p. m., April 7, 'o4.

The experiment began immediately after an afternoon lecture from which I felt tired. The step seemed too large throughout. There was no considerable period during which $I$ felt any distinct incapacity for discriminating. The mis. takes seemed to come singly, and most of them could be traced to some temporary inattention, movement, distraction, or lapse into rhythm. I was quite comfortable all the time. The darkness and silence of the room were distinctly restful and quieting. I felt a distinct relief from the strain of the lecture room and from stimulation of the eyes, and thought that this room would be an ideal resting place.

The work was not exhausting. There was a distinct tendency to automatism. It was possible to carry on a process of reasoning without making any mistakes in the discrimination. (?) It may be that the tendency to perceive rhythmic accentuation (intensification) led me to think that I was right when I was not.

The time seemed to drag, i.e., I kept accelerating and had to realize from time to time that my subjective standard of time had changed. I was sleepy once, at the end of the first fifteen minutes.

I had a distinct and helpful pitch association. The strong tone seemed to be the fundanental' (do) and the faint seemed to be the fifth of the octave below it (sol). I frequently judged entirely by this pitch difference, which was probably due to the prominence of the first overtone in the stronger sound.

VII. (M. C. W.), $3: 40$ p. m., June II, 'o3.

The quality of the tone varied. The time passed quickly, and I did not feel tired at the end. I had short lapses of attention which seemed to serve as periods of rest, but $I$ exerted a strong effort all the time. During the first fifteen 
minutes I felt dizzy. There was a strong space association, the weaker sound being localized further away.

\section{Series III. Memory.}

\section{Problem, Apparatus, and Method.}

The following requirements were kept in mind in the planning of this test: (I) The work shall consist of a difficult act of memory which shall be repeatable under uniform conditions, without interruption, for any desired length of time. (2) There shall be only one variable element in the complex act; all variable associations and disturbing sensory stimuli shall be eliminated as far as possible and the motor process shall be reduced to a minimum and uniform act. (3) All elements in the complete act of memory, namely, impression, retention, reproduction, localization, and expression, shall be involved in the same way at every step. (4) The work shall be the result of continuous maximum effort. (5) A detailed record of efficiency shall be obtainable.

With these ends in view, the following act of memory was chosen: Given four clearly distinguishable intensities of the same tone in succession, to signal the order of succession in a group after the order in the next following group has been observed.

The psychological relations of the intensities of the tones may be represented by the relations of these lines:

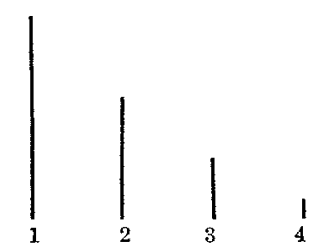

Number 4 was so faint that it could just be heard distinctly, I was as strong as it could be without being disagreeable to the ear, and 2 and 3 were adjusted between these limits empirically in such a ratio that the steps $\mathrm{I}-2,2-3$, and $3-4$ were equally perceptible.

The procedure may be illustrated from the beginning of an experiment by giving the part of the observer, as follows: 
Receives the first group, e. $g ., 2$ I 34 .

Receives the second group, $\epsilon . g ., 32$ I 4 .

Reproduces the first group, 2 I 34 .

Receives the third group, e. $g ., 24$ I 3 .

Reproduces the second group, 32 I 4 .

Receives the fourth group, e.g., 4 I 32 .

Reproduces the third group, 24 I 3 .

Receives the fifth group, e. $g ., \mathrm{I}_{42} 3$.

Reproduces the fourth group, $4 \mathrm{I}_{3} 2$. Etc.

Thus the same act, namely, observing the order of four sounds in a group and reproducing it after another group has becn observed, could be repeated for any length of time without serious change in the setting or relative value of the elements in the group. The selection of this particular act made it possible to comply approximately with all the five requirements enumerated above.

The sounds were produced through a telephone receiver in the secondary circuit of an inductorium, the primary circuit of which was completed as a shunt around a roo v. d. electric tuning-fork.

A system of four open-circuit keys was inserted in the primary circuit of the inductorium. Each of three of these was in circuit with resistance coils, respectively, as follows: key 2, 35 ohms; key 3, 67o ohms; and key 4, 4,845 ohms. By closing a key, the inductorium circuit was completed through the corresponding resistance and this change in the current produced the desired gradation of the sounds heard in the receiver. This gradation was determined empirically by a sufficient number of trials. The experimenter produced the stimulus sounds by playing upon these keys.

The observer signalled his reply by a similar system of keys, each of which was associated with a given sound. Thus, the sounds were numbered $1,2,3,4$, in order of their strength, beginning with the strongest, and the keys were numbered I, $2,3,4$, running from left to right. Hence, if the sounds appeared in the order $3,2,4,1$, the proper reply would be to press the response keys in that order.

A record of the stimuli and the responses was taken in a 
continuous tracing by the multiple recorder. ${ }^{1}$ Each of the stimulus keys was connected with a pen on the recorder, and each of the response-keys was connected with the same pen as the corresponding stimulus key. The fifth pen in the recorder traced a time-line in seconds. A portion of a record is reproduced in Fig. I5.

Each section contains first the group of four stimuli and then the group of four responses to the group received in the preceding section. Thus, the first response we cannot tell anything about because the stimulus is not on the record, but the second response is correct because it corresponds to the first stimulus group: the third response is wrong in part because it reads $4,2,3$, 1 , instead of $4,2, I, 3$; and the fourth response, again, is correct. The record also shows the time of each stimulus and each response.

In regulating the time-order, the experimenter was guided by the beat of a metronome. The record shows that the sounds were produced at the rate of one per second, and that each sound lasted one half second. It also shows that an interval of four seconds was allowed for each group response and that the individual responses were given short and in quick succession so that the observer saved some time in which to change from the expressive to the receptive mental attitude.

The apparatus was distributed in three rooms: the telephone receiver, the response keys, and the inductorium were kept in the observing room; the fork was kept in the distant battery closet, and the experimenter had the remaining parts in the measuring room. The observing room was moderately lighted with an incandescent light.

There are twenty-four possible mutations of the stimulus group with four sounds, but as two of Fig. 15. these (1234 and 432I) are decidedly easier than the

${ }^{1}$ See references. 


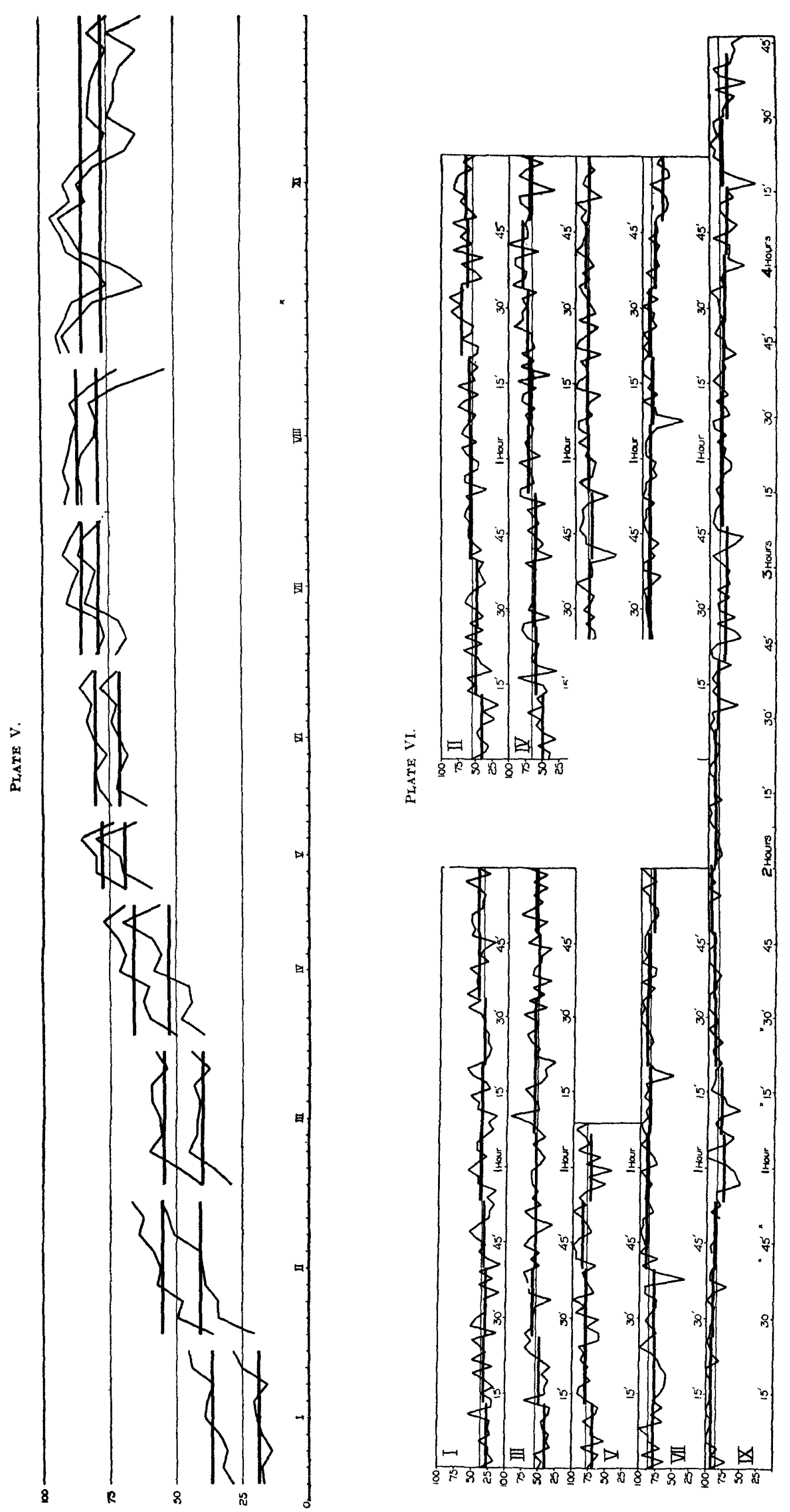


rest they were excluded and the remaining twenty-two mutations were used approximately in the order in which they would occur by chance.

The experiments here reported consist of a single series of nine periods taken upon one observer, Observer I., in Series I. and II., as follows:

LIST OF EXPERIMENTS.

\begin{tabular}{|c|c|c|c|}
\hline Experiment. & Date. & Began. & Continued. \\
\hline I. & Feb. 9 & 9:04 a. m. & 2 hours. \\
\hline II & " I I & $9: 04$ & $" 4$ \\
\hline III. & “ 16 & $9: 15$ & "16 \\
\hline IV. & " 18 & $9: 08 \quad$ & "1 46 \\
\hline V. & $\because 20$ & $8: 37$ & I hr. I3 min. \\
\hline VI. & $\therefore 23$ & $9: 14$ & 2 hours. \\
\hline VII. & " 25 & $9: 13$ & 64 \\
\hline VIII. & Mar. I & $8: 57$ & 466 \\
\hline$I X$ & $\because 3$ & $7: 29$ & 4 hrs. 48 min. \\
\hline
\end{tabular}

During experiment V., the repair man at the power house cut out the electric current without warning and, as the current was used in running the recorder, the experiment had to stop at that point. In experiment IX., the observer attempted to continue the test as long as he possibly could. After four hours and forty-eight minutes, he had to cease because his hearing had changed so much that he could no longer hear the faintest of the sounds in the stimulus group, although he had not reached the end of his endurance in other respects.

\section{Explanation of the Records.}

The tables of numerical results are too extensive to be introduced here, and they are not necessary, because the main facts may be represented in curves which give the true relief and show enough of the detail for the present purpose.

P1. V. shows the results of the whole series en gros. Each link in the curve as a whole represents one experiment period. The base-line is laid off in units of one hundred acts. Since each act takes eight seconds, these units may also be considered time units of eight hundred seconds, or 13.3 minutes each. The time-line extends one unit to the left of each curve because the beginning point in each curve represents a hundred acts. The per cent. of success is indicated by vertical distances. 


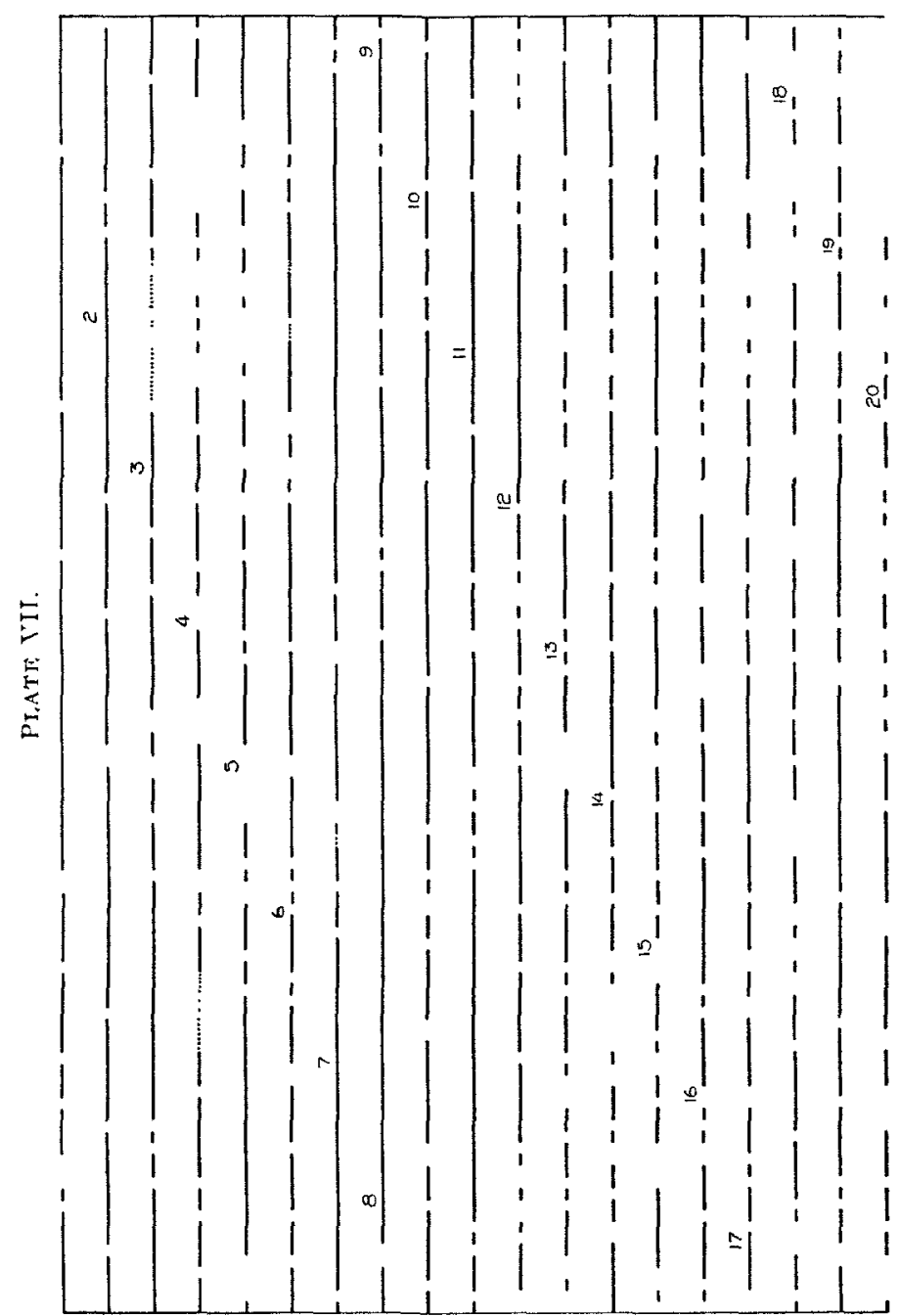

The degree of success is expressed in two curves which run nearly parallel. The upper indicates what per cent. of individual signals - out of a possible four hundred - were correct in each group of one hundred acts. The lower curve shows what per cent. of complete acts were correct in the same periods. The difference between the two curves is that successful parts of acts were counted for the former whereas only successful whole acts were counted for the latter. 
For the two-hour periods, there are nine points in each curve. The average for the whole period is expressed by a heavy horizontal bar over each curve. By these means we are enabled to see at a glance the general trend of the progressive change and the existence of the long periodic changes. The figure as a whole is a fatigue-curve, work-curve, memorycurve, curve of 'learning,' etc., according as it is viewed from one point or another.

Pl. VI. shows the same results more in detail. Here the record contained in the upper curve of $\mathrm{Pl}$. $\mathrm{V}$. - the per cent. of success, counting both whole acts and parts of acts which are correct - is represented in units of ten acts for each point. Each point in the zigzag curve denotes the average per cent. of success in ten acts. Averages for a hundred acts each are represented by the heavy horizontal bars, and averages for the whole record of a period by a light horizontal line. The numbers of the sections here, as in Pl. V., correspond to the list of periods, dates and durations in the above table. Pl. VI. shows the hour-waves and the minute-waves quite well.

Finally, to show the 'makes and breaks' in the continuity of power still more expressively, the data contained in the lower curve of period IX. are represented in a special manner in Pl. VII. Success in whole acts is represented by a line, and failures by breaks in the line. It shows the distributions of the ratios of success to failure. Thus, from the beginning, the record reads: Nine successes, one failure, one success, three failures, four successes, one failure, three successes, one failure, seven successes, etc. The three small-dotted parts indicate objective disturbances. The numbers indicate the ends of the successive hundreds of acts.

\section{Extracts From the Introspective Accounts.}

February 9. - At the beginning of the experiment, I attempted to find sume method to aid in the remembering. I tried to remember the sounds by their numbers, by directing special attention to the first two sounds in a group etc., but abandoned these in favor of the attempt to retain the sensory image of the group as a whole. This change of method produced great irregularities in the first part of the record.

February $1 I$. - To-day the series was not so fatiguing and no change occurred in the way of trying to remember the succession of sounds. Toward 
the last it seemed comparatively easy and it seemed that a small number of sound conbinations were used over and over.

February 16. - I do not think that this record is any improvement over the last one. I did not feel so bright as last time - possibly on account of the close air in the room. I could not concentrate attention so well. The period seemed longer than the last one. *** The strength of the sound series as a whole seemed to vary several times *** in the latter part the sounds seemed fainter for a short time.

February 18. - To-day's record is better than the last one, and possibly better than any preceding record. There were no special disturbances except twice, probably at the change of classes.

February 20 . - To-day's record is, I think, an improvement over the preceding. About 85 per cent. to 90 per cent. of the reactions may be correct. * * * The periods of attention and relaxation [minute-waves] seemed to have changed considerably. In the first and the second records I took, I should estimate that the periods of attention and relaxation are about equal, but in succeeding records the period of attention seems to have increased in length gradually.

February 23 and 25. - The observer wrote no introspective accounts on these days, because he had nothing special to record. He was aware of the continued practice gain and in both cases his estimates of the degree of his success was approximately correct.

March 1. - During the last part of this period the sound series seemed to grow stronger so that it caused confusion of the sounds. There were also some irregularities in the duration of the sound stimuli. The direct effect of these disturbances lasted for a short time only, but the thought of them tended to recur and was especially effective in distracting my attention because this took place in the last part of the record when I was fatigued and more subject to it.

March 7. - During the first few records I memorized the stimuli largely by visualization. I responded according to the impression of the successive louder or fainter sounds, not taking notice of particular ones of a group. Then I associated each stimulus with the key corresponding to it, and whenever a group was given I would glance from one key to the other in the same succession as the given stimuli. At the same time one or two of each group began to become more conspicuous on account of their position or intensity, $e, g$, the first and last ones of a group or the place of the loudest or faintest ones, but especially the former. If the first one and the last one of a group were together, $i . \mathcal{e}_{\text {, }}$ if the corresponding keys were together, they would be the more conspicuous ones. So my memorizing depended largely upon the reference to the key board. Some groups were more easily remembered than others. Such are, 1324, 423I, 2134, 1243, 342I, 3412, 234I, 3214. In these the conspicuous features were noticed more easily and much earlier than in the others. But the more difficult ones were also memorized in the same way but more slowly, so that some were not thought of by their peculiar features until the last two or three records. These noticeable features of the various groups afforded a basis for 'names' of the groups so that at last I had a name for each group as follows :

(The keyboard was thought of not as a horizontal plane but as an inclined plane of which the end with the loudest sound was up and the end with the faintest sound was down.) 


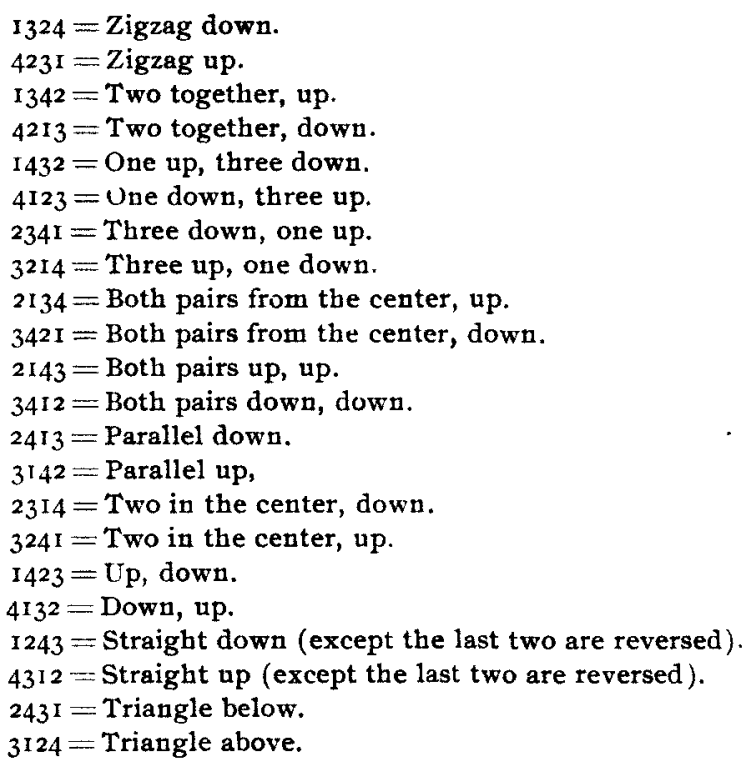

It never occurred to me until now that the remembrance of these groups depended so much upon the motor action of my right hand as it really does. As I am writing these groups and their 'names' I cannot give many correctly without actually performing the taps as if on the keyboard. After these names had become quite familiar, I had a feeling of confidence that I could give almost every response correctly unless I had been too inattentive to get the group correctly when it was given. Whenever I had clearly grasped a group I was certain that I could remember it with the aid of its names and give it correctly in the response. But before $I$ had these names for the groups the occurrence of the second group would frequently cause me to forget the first, although I had it clearly in mind just after it had been given.

During the intervals between the stimuli $I$ repeated the name of the group to be given after the next stimulus by actual movement of the mouth. I was unconscious of it and did not know it until I caught myself doing it. The movement of the hand in giving the response was almost entirely automatic so that I needed to attend only to the incoming stimuli. I was also unaware of breathing except when I happened to take a deep breath.

During the last record fatigue did not consciously affect me until about the end of the third bour. I became inattentive on account of a drowsy, sluggish or sleepy feeling. Whenever I would take a different position on the chair it would serve to make me more attentive. About a half hour before the end of this record I occasionally felt a stinging pain in my ear. This became more frequent and intense until the fourth or faintest sound was not perceptible at all, and then I decided to stop.

For nearly an hour after, I felt pain in the ear from time to time. I did not seem to be fatigued very much until two or three hours afterward. I felt as though I had done hard manual labor. 
In reply to a request for fuller information in regard to the disposition of the time allowed for an act, the observer wrote, under the date of March 18 :

As each sound of a combination was given, I glanced at the corresponding key and as soon as the third sound was heard, I knew the whole combination of four sounds so that, immediately after the last sound, I could turn to the preceding combination and respond at once. The reaction was almost automatic. After the response, I returned to the new combination and repeated its name but discontinued this long enough before the appearance of the next sound to be fully prepared. If I failed to allow time for preparation, I frequently failed to get the new combination.

\section{Periodic Change: A. Hour-zuaves.}

The hour-waves are quite as pronounced and uniform in this series as in Series I. and II. They may be seen both in Pl. V. and Pl. VI. Thus running the eyes along the curves in these plates, we see two and one half sinoid waves in each of Periods I., III., VII., and VIII. ; three waves in Periods IV. and VI.; three and one half in Period II. ; and one in Period $\mathrm{V}$., which is incomplete. (Cf. the records on the same observer in Series I. and II. - Fig. I., Pl's I., and IV.)

About the same lengih of waves are found in Period IX., but they are here disturbed by the presence of longer waves which seem to be due to the awareness of the length of the task. The great depression of the long wave, one phase of which occupies two hours, is due in part to a temporary disturbance, the stopping of the fork. The points at which the forks stopped are marked with stars in the figures. These disturbances were only of a few seconds duration each and the loss is eliminated in the averaging for the groups in which it occurred.

\section{Periodic Change: $B$. Minute-waves.}

The same minute-waves which we are familiar with from the other series are here in evidence. They appear conspicuously in Pl. VI. in which their regularity is somewhat exaggerated by the want of detail. To show them with absolute fidelity, the record for Period IX. is represented in detail in Pl. VII. but here it is difficult to trace them on account of the confusion of these with the longer waves. 


\section{Periodic Change: C. Second-waves.}

Here as in the preceding series the second-waves are present and can be obtained by analysis of the act and introspection. The form and combination of the attention-waves go through progressive changes throughout the series. For the purpose of simplifying the presentation, we may examine the distribution at a given stage, $e . g$. , the last record.

Fig. I6 shows in a schematic way the form and composition of the wave in a typical act at this stage, the stage of the highest mastery of method. The long bars I, 2, 3, 4, represent the time of the four stimuli in the group which is to be impressed. The short bars $4,3,2$, I, show the time of the responses to the impression received in the preceding act. ${ }^{1}$ There

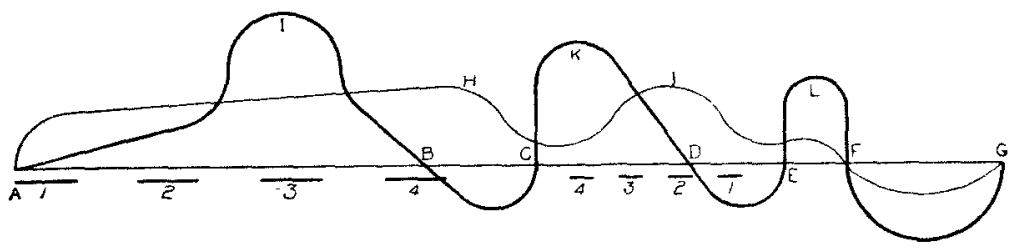

FIG. I6.

are three waves of active attention: $A-B$, to the act of receiving; $C-D$, to the act of responding; and $E-F$, to the repetition of the group which is to be retained. After each of these, there is a depression denoting the absence of this form of attention. The wave of passive attention is continuous for this act, although it shows certain characteristic fluctuations. A glance at the curve reveals these fluctuations better than a verbal statement.

The distribution complies with the general requirement, that the active attention shall be more impulsive and take more rest than the passive. Both forms have negative phases from $F$ to $G$, but the active attention has two other pronounced negative phases, namely, $B-C$ and $D-E$.

The receiving process clearly divides itself into active and passive stages. The crest, $I$, denotes the fact that, at the beginning of the third stimulus in the group, the fourth was pre-

' By mistake in lettering, the two orders, I 234 and $432 \mathrm{I}$, which were not used, appear in the figure. 
dicted and the order of the group was analyzed and impressed, by a well concentrated effort. After a moment's relaxation, there was another decisive mustering of forces in the act of recalling the order which was to be reproduced; the motor process of the response was semi-automatic. Following another moment of relaxation, there was a short but well regulated effort, $L$, in the reviewing of the image which was being retained. Then both forms of attention drop in preparation for renewed efforts.

The actual distribution varies from the type described, not only in the series as a whole, but in successive acts at this particular stage of practice. In fact, the progress of learning might be illustrated in terms of the progressive change in the composition of the attention-wave. So also every temporary fluctuation in efficiency may be described partially in the same terms.

This leads us to the question, Is it possible to maintain a perfect record for two hours in this particular act? All we can say is that the elimination of occasional errors would be an extremely slow and difficult process. The attainment of perfection depends upon the power to adhere to a most economic composition of the attention-wave. The distribution of failures, as shown in Pl. VIl., indicates that it is possible to be systematic and successful for a considerable period at a time, but the hour and the minute-periodicities break in and the result is disturbance in the second-wave.

\section{Progressia' Change.}

Examination of the curves in $\mathrm{Pl}$. V., with reference to progressive change, reveals especially the following features: (I) There is a gradual increase in efficiency from the beginning to the end of each of the first seven periods, provided one neglects the periodic fluctuation and regards only the general tendency. The second and fourth periods show the greatest rise, and the third and sixth the least. (2) Periods VIII. and IX. both show progressive decline in efficiency. (3) There is a tendency for each successive period to start from the vantage-ground gained in the just preceding period. The rise of the series, however, shows three plateaus; the third day is on the same level as 
the second; the sixth is on nearly the same level as the fifth; and the eighth and ninth are on about the same level as the seventh. (4) With increasing efficiency, the two curves tend to run closer together.

The curve as a whole is a practice-curve, but not pure and simple, for various other elements are involved in it. The act was appallingly difficult to the beginner. It was so much more than he could do that it required the greatest determination and perseverance in pursuit of the goal - mastery by practice. This goal he never quite reached, yet he came near it, and made a remarkable progress with practice. What was the nature of the improvement? The discussion of that might be considered the principal topic of this report, but we must content ourselves with merely a brief reference to it.

According to the observer's account, supplementing his written introspection, the following were important factors in the learning, or acquisition of power by practice: (I) Distributing energies, (2) finding method of receiving, (3) development of a visual scheme of associations, (4) automatism of the response, (5) naming, (6) repetition, and (7) rest.

Before the recording began, the observer had had no more practice with this act than was necessary to enable him to understand the requirements. At the first attack there was naturally a good deal of hesitation as to what part of the act he should concentrate his energies upon first. It was impossible to give uniform attention to the whole array of parts in the act.

This led to a skirmishing for methods - methods of receiving, methods of retaining, methods of reproducing. This skirmish was most noticeable during the first third of the first period. As a rule he was not aware of deliberately trying this or that method; there was a sort of desperate effort to get something in any way possible, and reflection shows that this resulted in the bobbing up of different methods which may be differentiated.

The general method soon found and afterward followed consisted in falling back upon a very concrete visual scheme of . associations which grew gradually toward perfection and real- 
ism. The scheme was not merely visual; the motor element was prominent and contributed much to the realism. Consciousness was distinctly visual-motor. The situation was alive! The observer became oblivious to all else and threw himself entirely into this melee. It was not abstract memory; it was a play. Each sound was merely the signal of a combatant who had to be located and his lunge parried.

The development of power in this act of parrying consisted in the formation of automatisms, just as the acquisition of skill does in the fencer. From this point of view, this act of memory resolved itself into a hierarchy of acts in which one grade after another was mastered in succession.

Still improvement consisted largely in progressive unification. Groups were gradually identified as wholes having striking peculiarities which gave rise to names. The names were descriptive and served as motor cues. The identification and naming led to the perception of the limitation of the number of variations, and this resulted in the development of a feeling of familiarity and ease which was decidedly conducive to endurance.

All these shortenings increased the spare time and it soon became possible to take advantage of that by recalling the impression which was to be retained while waiting. This repetition strengthened the retention as soon as it could be done without too much sacrifice of rest.

But the acquisition of time for rest and the habit of the most economical use of this rest constitute the most potent factors in the development of power of endurance.

Features like those here enumerated account for the profit by practice up to the highest point reached. That point seems to be approximately a physiological limit.

The observer accounts for part of the decline in Period VIII. on the ground of objective disturbance. That disturbance seems to have been overestimated and was probably chiefly subjective, but it brought on a mood or attitude which is the chief cause of the depression. For this reason, it is not safe to draw any conclusion in regard to progressive change in this period, except to state that a decline occurred. 
The decline in the long final period is pronounced and decisive.

\section{Part IV. General Conclusions.}

The conclusions upon individual points are so tersely stated in the text that there is no need of repeating them here; but it may be profitable to restate some of the broader generalizations from the investigation as a whole, stripped of their technical garb.

Our primary aim was to develop methods of controlling and recording definite forms of continuous mental work in the hope (I) that we might pave the way to the experimental study of such facts as fatigue, adaptation, learning, and the effect of various conditions and stimuli upon the efficiency of continuous work, and (2) that certain general characteristics of mental work might be demonstrated in such faithful records. The results may, therefore, be summed up with reference to (I) method, and (2) certain characteristics of the efficiency of continuous mental work: $(a)$ periodic change and $(b)$ progressive change.

\section{Method.}

The methods here introduced for the measuring of prolonged mental work differ essentially in type from the methods in vogue, such as the adding method, the nonsense syllable method, routine work methods, the ergograph method, etc. Our methods seem to have advantage over every other method heretofore used in one or more of the following respects :

The work is mental.

The work is relatively homogeneous.

The work is reduced to fundamental types and relatively controllable conditions.

The measurements are continuous and in sufficient detail.

The measurements are on the work itself and not on injected tests.

The general principle is adaptable to different types of mental work. ${ }^{1}$

I It takes but little ingenuity to adapt the general principle of measurement here employed to the different senses, and to fundamental types of cognition and action. But this is only the first step; the methods must be used under specific conditions for specific purposes, $e . g$, by Kraepelin's pause-method in the study of fatigue. 


\section{Periodicity.}

I. Periodicity a General Characteristic of Mental Work. ${ }^{1}$ - The three fundamental and representative types of mental actıvity studied, sensation, discrimination, and memory, exhibit alike a thoroughgoing periodicity. There is a continuous gradation from the period of the momentary active impulse up to the hour-long waves of mental efficiency. The efficiency in a given period, say two hours, may be represented by an irregular wave, the resultant of a series of partials.

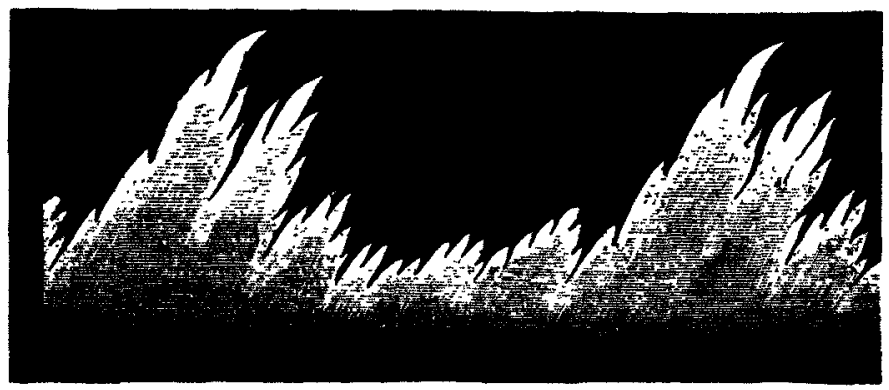

FIG. 17.

Such a wave is analogous to the synthetic wave made by combining the fundamental and a dozen or more series of partials of a vibrating string. The typical fuctuations in mental efficiency under these conditions might well be represented by the well-known composite curve from the manometric flame shown in Fig. 17 .

2. Second-waves. - Such periods of mental activity as are grasped in uninterrupted waves of attention.

Attentive work runs in elementary periods the length of which depends upon the individual and conditions of work but does not ordinarily extend more than a few seconds.

The attention-wave of Urbantschitsch is typical of this perio. dicity whether the stimulus is strong or weak, constant or variable, objective or subjective.

1 The word periodic is not used here in the mathematical sense of exact equality, but in the sense of approximate or relative equality of period. The factors which condition the fluctuations are so exceedingly complex and variable that there is no reason to expect such beautiful and exact symmetry as is shown in Fig's 16 and 17. 
This wave is composite: it consists of relatively long waves of secondary passive attention and one or more relatively short waves of active attention.

Active attention appears only at the crucial points; the bulk of the second-wave is secondary passive attention. Active attention constitutes the determining moments and secondary passive attention bridges the gaps between these.

In a complete attention-wave, $i . e$, a second-wave, there is one moment at which both active and secondary passive attention are at rest (not present). Unless the act consists of a single impulse, there are two or more moments of rest from active attention, but the secondary passive attention never has more than one.

The second-wave is irregular in outline, being the resultant of two components which vary with the individual and the conditions of the work.

3. Minutc-zuves. - Periods which contain more than one second-wave but are less than twenty minutes in average length.

Beyond the second-waves, attentive work runs in short composite waves; these combine in series as partials of longer waves and exhibit the phenomena of interference and reinforcement.

When the work is such that it may be perfect for considerable periods of time, as $e . g$, the memory work after long practice, these waves do not show in the objective record, but introspection reveals their presence through fluctuations in ease, certainty, concentration, etc., and through awareness of mindwandering, ennui, dullness, and other more or less certain accompaniments of change in capacity.

4. Hour-waves. - Periods lying between the minute-waves and the well-known diurnal waves in length. ${ }^{1}$

Beyond the minute-waves, attentive work runs in one or more series of long composite waves of efficiency. These are distinguished from the minute-waves because they are probably the result of different conditions from those which underlie the shorter waves.

'By diurnal waves, we mean such daily rhythms in efficiency as are due to routine work, eating, sleep, recreation, etc. 
The hour-waves tend to get shorter as the work progresses.

There is no evidence of any constant tendency of observers to begin the work at the moment of greatest efficiency, or any other particular phase of the work curve.

5. Correlation of Changes. - Keenness of sensibility (To) and alertness (threshold width) are not closely correlated.

Keenness of sensibility ( $T o$ ) and variability (mean variation), are not clasely correlated.

In these two cases it is not so much a question of degree of correlation as of type of tendency; some individuals give a high positive correlation and others give an equally high negative correlation.

Large variability (mean variation) and lack of alertness (threshold width) are highly correlated.

6. Individual Types. - There are evidences in these records to show that each individual probably has a fairly characteristic type of waves for similar work done under similar circumstances but at different times. This is true of all, from the short second-waves to the long hour-waves. This individual characteristic may show even in as radically different work as the three forms here employed.

7. Consciousness of Change.-The shorter the wave, the more clearly the observer is aware of the change. Introspection can always grasp the second-waves, but hour-waves may have large amplitude without the observer's suspicion of their existence.

The feeling of dullness does not correlate closely with poor work in waves of medium length. The very feeling of dullness comes from awareness of exertion. Low efficiency correlates better with periods of unconscious neglect, absentmindedness, mind-wandering, etc., which become known only as we catch ourselves in such shortcomings and forthwith make a new start.

8. The Significance of Periodicity. - The experiments were not planned so as to test any theory of the cause of all this periodicity, but it is reasonable to suppose that they are all evidence of nature's way of protecting the organism; the periods of dullness are periods of relative rest from which the observer 
comes forth refreshed. It is common to speak of the failing of voluntary attention as nature's safety valve; the same figure may be extended to the whole series of periodicities.

Fatigue, practice, and adaptation errors have received critical examination in experimental method, but in these periodicities we have a factor which in many forms of experiment is as important as any of those named. In measurements for comparison which run over half an hour or more, what is only a part of wave may be taken for progressive change. This is especially so if the experiment is repeated in the same order and on the same observer who may have a definite type of periodicity.

This periodicity favors our normal working in short periods. When composing, $\varepsilon . g$., one writes during a moment of lucidity and then relaxes intc a state of ennui and feeling of restriction, only to take up the period again. In free work such as that, the fluctuations are very much greater (and perhaps more efficient) than in work under experimental pressure. ${ }^{1}$

It has often been observed that, even in a situation of life and death, these periods of relaxation and absence of power set in, to our moral shock and great discomfiture.

These fluctuations are a part of nature's great scheme of rhythm. They are a condition of endurance and progressive mental development.

Their significance is analogous to that of sleep.

One may discover his most favorable rhythms and adapt his work to these. The art of effective work consists largely in selecting the most favorable rhythms, both long and various partials.

\section{Progressive Change.}

I. General Tendency of Change in Efficiency. - These experiments were not planned to isolate the factors which form a basis for progressive change. The aim was rather to secure faithful measurements of the actual efficiency from moment to

1 Thus, the end tests in Series I. on the effect of a liminal sound upon the ear used and the ear not used in a two-hour period depend upon what phase of the long waves they are taken in. This is the chief reason why we could not draw any definite conclusion from those tests. 
moment, regardless of the underlying shift of elements. Yet certain important progressive tendencies may be seen in the records.

2. Practice.-There is no noticeable gain from practice in simple perception and simple discrimination, after the observer has clear knowledge of the nature of the stimulus.

The improvement in a complex cognitive act, such as memory, is very great.

The improvement in memory work may be ascribed chiefly to progressive systematizing of parts in the act, the development of automatisms, the association of concrete imagery, and economical rest.

The practice is effective in impression, retention, reproduction, localization, and expression; but there is a tendency to make gain in one of these factors at a time. This leads to the step-like or plateau series of progressions.

The marked practice improvement ceases when the observer has reached the limit of his inventive power in systematizing. ${ }^{1}$

3. Fatigue.-Continuous liminal or moderately faint sounds do not seem to lower the efficiency of the ear in a two-hour test.

In the long period of the memory test, the faintest sound, which was clearly above the threshold at the beginning, became inaudible during the fifth hour of the work. There is nothing to show whether this is due to the long continuation of the work or to the stronger sounds in the group; nor was the test continued to determine whether this loss of sensibility was evidence of progressive or periodic change.

We failed to differentiate between the central and the peripheral fatigue by means of the 'before'- and ' after'-tests.

4. Adaptation. - Since the sensibility tests show no unmis-

${ }^{1}$ From the suggestion contained in these records, and from the accumulation of experimental evidences not published, we are inclined to believe that there is a general law which expresses the probability of gain by practice in any form of mental activity. This law is, The practice gain is somewhat proportional to the complexity of the act. In other words, where there is room for noticing new factors and simplifying, there is promise of practice gain. Simple perception and simple discrimination in the above records do not show any practice gain because the acts were sinple, but the conditions of either could easily have been made so complex that there would have been a greater practice gain than in memory. 
takable general rise or fall in efficiency and the discrimination tests show a fairly decisive decline; and since the strain of attention is about equal in the two tests and change in peripheral sensibility would have but little significance in the latter, it appears that there may be a general decline of central efficiency in both tests and that this is counteracted in some cases of the sensibility tests by an increase in the peripheral sensitiveness through adaptation.

5. Types. - The observers conform to different types with reference to progressive change. They may be divided first into those which show general gain and those which show general loss. Then each of these may be subdivided with reference to the rate of change and with reference to the time and cause of change. 